\title{
UN NUEVO COMPLEJO RELIGIOSO DE ÉPOCA IMPERIAL EN COLONIA PATRICIA. EL RECINTO DE CULTO DE C. TEJÓN Y MARÍN 14 (CÓRDOBA)
}

\author{
A NEW RELIGIOUS COMPLEX FROM THE ROMAN IMPERIAL AGE IN COLONIA PATRICIA. \\ THE PLACE OF WORSHIP IN TEJÓN Y MARÍN STREET 14 (CÓRDOBA)
}

\author{
ANA PORTILLO GÓMEZ \\ Universidad de Córdoba \\ aportillogomez@gmail.com \\ http://orcid.org/0000-0003-0051-846X \\ MANUEL D. RUIZ BUENO \\ Universidad de Córdoba \\ mdruizbueno@gmail.com \\ http://orcid.org/0000-0001-9265-6979
}

Recepción: 14-03-2017

Aceptación: 05-06-2017

\section{Resumen}

En este artículo damos a conocer un complejo cultual romano descubierto hace unos años en Córdoba y que, hasta la fecha, ha permanecido inédito. Gracias a la revisión y al estudio crítico de la documentación disponible, hemos podido identificar un recinto sacro público o semipúblico levantado a finales del siglo I a.C. a escasa distancia de la muralla, y que con posterioridad (segunda mitad del siglo I d.C.) fue reformado puntualmente. Se trata de uno de los escasos recintos religiosos urbanos intramuros (al margen de los fora) documentados arqueológicamente hasta la fecha en Hispania, y además uno de los más antiguos. Dicha circunstancia ha motivado un estudio en el que hemos profundizado en aspectos como su inserción topográfica y su caracterización arquitectónica. Asimismo, también hemos optado por examinar su proceso de abandono (siglo IV) y su posterior reocupación funeraria y doméstica (siglos IV-VI), contextualizando la información disponible a escala local y supralocal con el fin de proporcionar una imagen lo más completa posible.

Palabras clave. Córdoba; arquitectura religiosa; templa; collegia; época augustea; Antigüedad Tardía.

\begin{abstract}
The aim of this contribution is to share an unpublished Roman religious complex discovered some years ago in Cordoba. Thanks to the review and the critical analysis of the available information, it has been possible to identify a public or semi-public cult building erected by the end of the first century BC. Located very close to the perimeter wall, it was remodelled in the second half of the first century $\mathrm{AD}$. At this moment, it is one of the few religious buildings in urbe (apart from the fora) archaeologically documented in Hispania, and probably one of the oldest. For these reasons, we have carried out extensive research about some features of the religious complex such as its topographical position and its architectural style. We have also looked into why it was abandoned in the fourth century $\mathrm{AD}$, and its later domestic and funerary reoccupation (fourth to sixth centuries $\mathrm{AD}$ ). We have put the available local information in its context and taken its wider geographical context into account, in order to give the fullest possible picture of this ancient building.
\end{abstract}

Key words. Córdoba; religious architecture; templa; collegia; Augustan Age; Late Antiquity. 


\section{INTRODUCCIÓN ${ }^{1}$}

Entre las múltiples consecuencias derivadas del pasado boom inmobiliario, destaca la extraordinaria multiplicación de excavaciones arqueológicas urbanas en núcleos como Córdoba. La característica vorágine constructiva generó un ingente volumen de información arqueológica que en muchos casos continúa inédita, pese a su relevancia para la comunidad científica. Es el caso de la Intervención Arqueológica de Urgencia (en adelante I.A.U.) desarrollada en 2003 en c. Tejón y Marín 14, y que implicó la realización de dos cortes, posteriormente unidos en uno solo. La excavación de una superficie total de casi $153 \mathrm{~m}^{2}$ supuso la detección de una compleja secuencia estratigráfica que abarca los últimos dos milenios. Entre las distintas estructuras identificadas nos interesa especialmente el hallazgo de un complejo cultual romano compuesto, como mínimo, por un recinto porticado, un templo y un altar.

A pesar de la condición de Córdoba como caput provinciae bético, nuestro nivel de conocimiento sobre su arquitectura sacra sigue siendo muy limitado. $\mathrm{Si}$ excluimos los testimonios puramente epigráficos (Barroso, 2015), en el estado actual de la investigación solo hay evidencias materiales seguras de dos templa que han sido objeto de diversos estudios en fechas recientes. Por un lado tenemos el templo del conocido como forum novum, posible foro provincial de la Bética, investigado de manera monográfica por uno de nosotros en su tesis doctoral (Portillo, 2016); por otro, el edificio religioso que presidía el complejo cultual de la c. Capitulares, cuya exacta cronología y advocación sigue siendo debatida (Garriguet, 2015; Gutiérrez, 2016).

La I.A.U realizada en c. Tejón y Marín 14 también permitió rastrear con notable precisión el abandono y el posterior destino del vetusto complejo sacro. Aun cuando el destino de la arquitectura cultual romana es un tema de candente actualidad e interés, su análisis resulta problemático en ciudades como Córdoba. El reducido tamaño de los solares, la escasa superficie exhumada o las alteraciones en la secuencia estratigráfica, son factores que han dificultado dicho estudio,

1. La elaboración del presente artículo hubiese sido imposible sin la ayuda de un variado elenco de profesionales a quienes agradecemos sus distintas aportaciones y comentarios: a D. Antonio Molina Expósito, director de los trabajos arqueológicos practicados en el solar $n^{\circ} 14$ de la calle Tejón y Marín durante los meses de mayo y junio de 2003 en la ciudad de Córdoba, y a quien damos las gracias por toda la documentación que nos ha proporcionado sobre dicha intervención, así como el buen trato, disposición y amabilidad que ha mostrado siempre con nosotros; al Dr. Antonio Pizzo, por las observaciones realizadas sobre la técnica edilicia del complejo objeto de estudio; y a D. Jose María Tamajón Navarro por la elaboración de las distintas planimetrías y reconstrucciones en $3 \mathrm{D}$ del recinto cultual cordobés. que no ha empezado a ser abordado en profundidad hasta fechas recientes (Ruiz Bueno, 2016: 551 ss.).

Las circunstancias anteriormente descritas permiten explicar el trabajo que a continuación presentamos, destinado a analizar ${ }^{2}$, reinterpretar, contextualizar y dar a conocer un recinto cultual que ha permitido mejorar nuestro grado de conocimiento sobre la arquitectura pública y semipública de Colonia Patricia, pero también de la topografía e imagen de la Corduba tardoantigua.

\section{INSERCIÓN TOPOGRÁFICA}

El solar objeto de nuestro estudio se ubica en la «nova urbs», es decir, en el sector correspondiente a la ampliación de la primitiva urbe republicana hacia el río (Fig. 1). Hacia 169/168 o 152/151 a.C. aconteció la fundación de Corduba, posible colonia Latina, sobre un espolón de la terraza cuaternaria del Guadalquivir, rodeado por tres de sus lados (todos salvo el septentrional) por acusadas laderas y varios arroyos. Se trataba de un asentamiento de una enorme extensión (47 hectáreas) situado unos $750 \mathrm{~m}$ al noreste del asentamiento indígena previo y a más de $420 \mathrm{~m}$ de distancia del río Guadalquivir (Vaquerizo y Ruiz, 2014: 16-18). Dicho esquema se alteró notablemente a partir de 45 a.C., cuando la ciudad fue asediada y posteriormente destruida por las tropas cesarianas durante el conflicto civil que enfrentó a Julio Cesar contra los hijos de Pompeyo. Tras este episodio traumático, la ciudad comenzó un desigual período de recuperación que supuso, entre otras actuaciones, el derribo del lienzo meridional de la muralla republicana, y la ampliación de la urbe hasta el río, alcanzando en el siglo I d.C. una superficie intramuros cercana a las 78 hectáreas (de las cuales 31 corresponden a la nova urbs). Aun cuando tradicionalmente se ha defendido que dicho ensanche tuvo lugar en época augustea (antes de 14 a.C.), en los últimos años se ha propuesto que hacia 44 a.C. acaeciese una deductio colonial por parte de C. Asinius Pollio que implicó, entre otros cambios, el arranque de la citada ampliación (Ventura, 2009: 377).

Con independencia de una u otra hipótesis, desde momentos tardorrepublicanos el solar correspondiente a c. Tejón y Marín 14 se ubicó intramuros, y de manera más concreta, a escasa distancia de la muralla.

2. El trabajo que aquí presentamos se basa exclusivamente en el estudio de la documentación textual, gráfica y planimétrica de los restos arqueológicos hallados durante la I.A.U. Desafortunadamente, no hemos podido analizar in situ las distintas estructuras exhumadas, al estar ocultas bajo una serie de niveles terrizos destinados a habilitar el solar como parking. Tampoco hemos tenido la oportunidad de revisar el material mueble recuperado en las distintas unidades estratigráficas, por lo que no siempre hemos sido capaces de precisar y confirmar las cronologías propuestas en el informe de la I.A.U. 
Gracias a un pequeño sondeo llevado a cabo frente a c. Tejón y Marín 20 pudo individualizarse un muro levantado hacia mediados del siglo I a.C., y posteriormente reconstruido en época de Tiberio-Claudio (Ruiz Lara et al., 2004: 44-45). Se trata de un paramento que formaba parte del lienzo occidental de la muralla que rodeaba a la nova urbs y que se situaría a escasa distancia de una de las principales puertas que jalonaban el recinto romano. Por el momento, la documentación sobre dicho acceso (perpetuado hoy en día en la conocida como «Puerta de Almodóvar»), se limita a un capitel corintio de pilastra fechado en época augustea o julio-claudia adscrito a la porta romana (Márquez, 1998: 192-194).

Más limitada y fragmentada es la información acerca del callejero in urbe en esta zona (Fig. 1). Las intervenciones arqueológicas llevadas a cabo en la nova urbs han permitido identificar varios kardines y un decumanus que delimitaban insulae con una orientación NO-SE y unas dimensiones teóricas de 1 x 2 actus, es decir, unos $35 \mathrm{~m}$ de ancho por 70 de largo (Carrillo et al., 1999: 47; Murillo, 2010: 78-79). Lamentablemente, la mayor parte de los datos proceden del sector más cercano al río Baetis, por lo que ignoramos la disposición viaria exacta en la zona de transición entre la vetus y la nova urbs, donde se sitúa el solar objeto de nuestro análisis.

Las evidencias más antiguas de ocupación individualizadas durante la I.A.U. se remontan a época republicana, cuando han sido fechados los restos de un edificio orientado en sentido NO-SE e interpretado como una vivienda (corte 1). Se trata de un inmueble del que conocemos un patio rectangular o cuadrangu$\operatorname{lar}^{3}$, dotado de una canalización perimetral y al que se abrirían varias estancias pavimentadas, en algún que otro caso, con una superficie musiva blanca sin ningún tipo de motivo decorativo (Molina, 2003: 50-51). Si nos atenemos a indicadores como el uso de sillares de calcarenita o la presencia de un suelo de signinum, es posible que nos encontremos ante un edificio levantado a partir de inicios del siglo I a.C. en adelante. En estos momentos las viviendas cordubenses entraron en una primera fase de monumentalización que supuso el empleo de nuevas técnicas y materiales constructivos como opus quadratum para los muros, tegulae para las techumbres, o «pavimentos de opus signinum, con o sin decoración de teselas blancas de caliza o cuarcita» (Vaquerizo, 2005: 188). Más difícil es poder determinar su carácter inicial in urbe o suburbano, puesto que al ignorar su cronología exacta no podemos determinar si inicialmente tuvo un carácter extramuros

3. Dotado en una de sus esquinas de una basa de columna lisa elaborada en piedra arenisca, compuesta por una pieza rectangular de la que emerge un imoscapo tallado en el mismo bloque, sin que existan molduras de división y/o conexión entre las partes. Presenta un aspecto tosco, una talla rudimentaria y una superficie irregular sin ningún tipo de elemento decorativo.

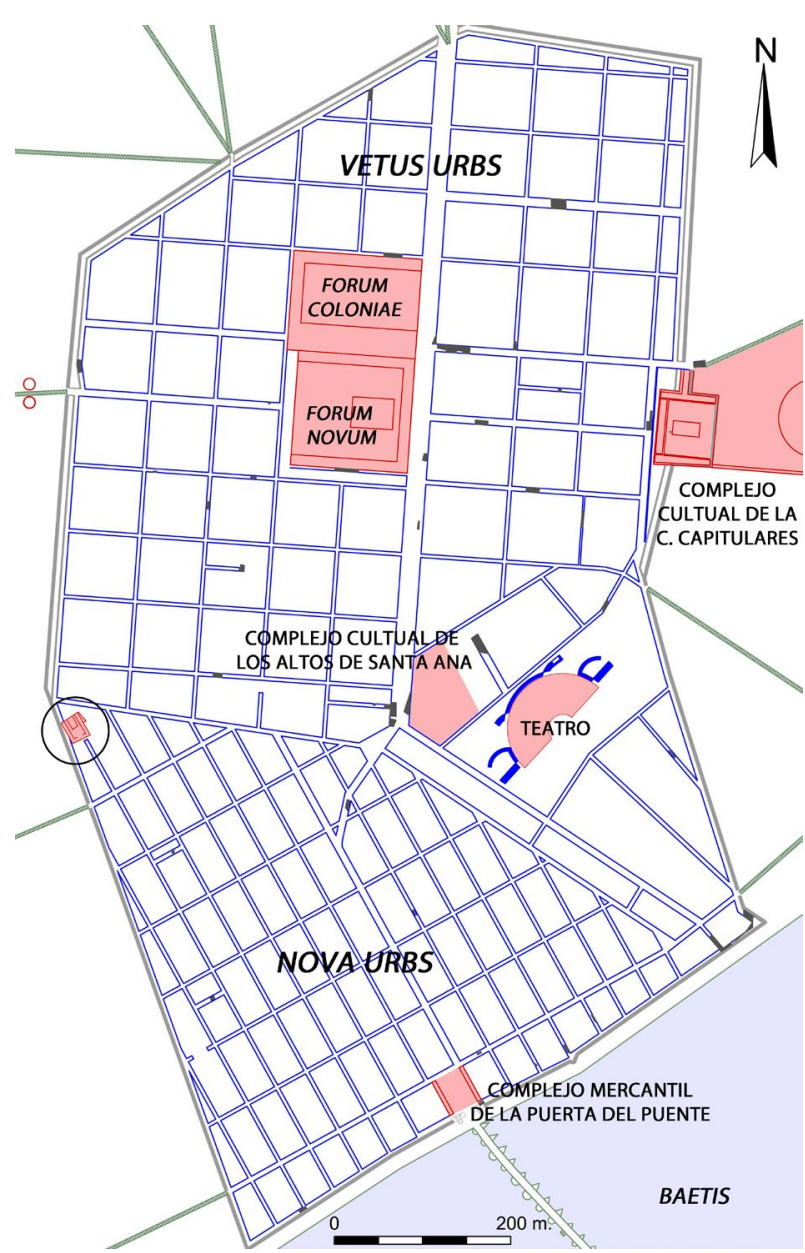

Figura 1: Reconstrucción hipotética del callejero in urbe de Córdoba hacia el año 100 con indicación tanto de las vías conocidas hasta el momento, como de algunos de los principales monumentos públicos de la Córdoba romana. El círculo indica la ubicación del recinto de culto de c. Tejón y Marín 14. Modificado a partir de Ruiz Bueno, 2016: planos 3 y 4.

(formando parte quizás de algún vicus ${ }^{4}$ ), o si desde un primer momento su construcción tuvo lugar en el marco de la lenta pero progresiva urbanización de la nova urbs. En cualquier caso, nos encontramos ante una vivienda que no superó el siglo de vida, puesto que a finales del siglo I a.C. quedó destruida con motivo de la construcción de un complejo cultual. Se trata de un conjunto con una orientación bastante similar a la del resto de las estructuras levantadas en la nova urbs, y que probablemente tuvo que adaptarse al espacio disponible. Esta circunstancia, junto a su cercanía a la muralla, podría explicar la presumible privatización parcial del intervallum aledaño al recinto defensivo, dado que la restitución simétrica del conjunto sacro apunta en dicha dirección (Fig. 1). No obstante, tal

4. La ciudad empezó a expandirse más allá de sus murallas desde fechas bastante precoces. Es el caso del vicus suburbano oriental, surgido en época tardorrepublicana o augustea $(\mathrm{Mu}-$ rillo et al., 2009: 693-694). 


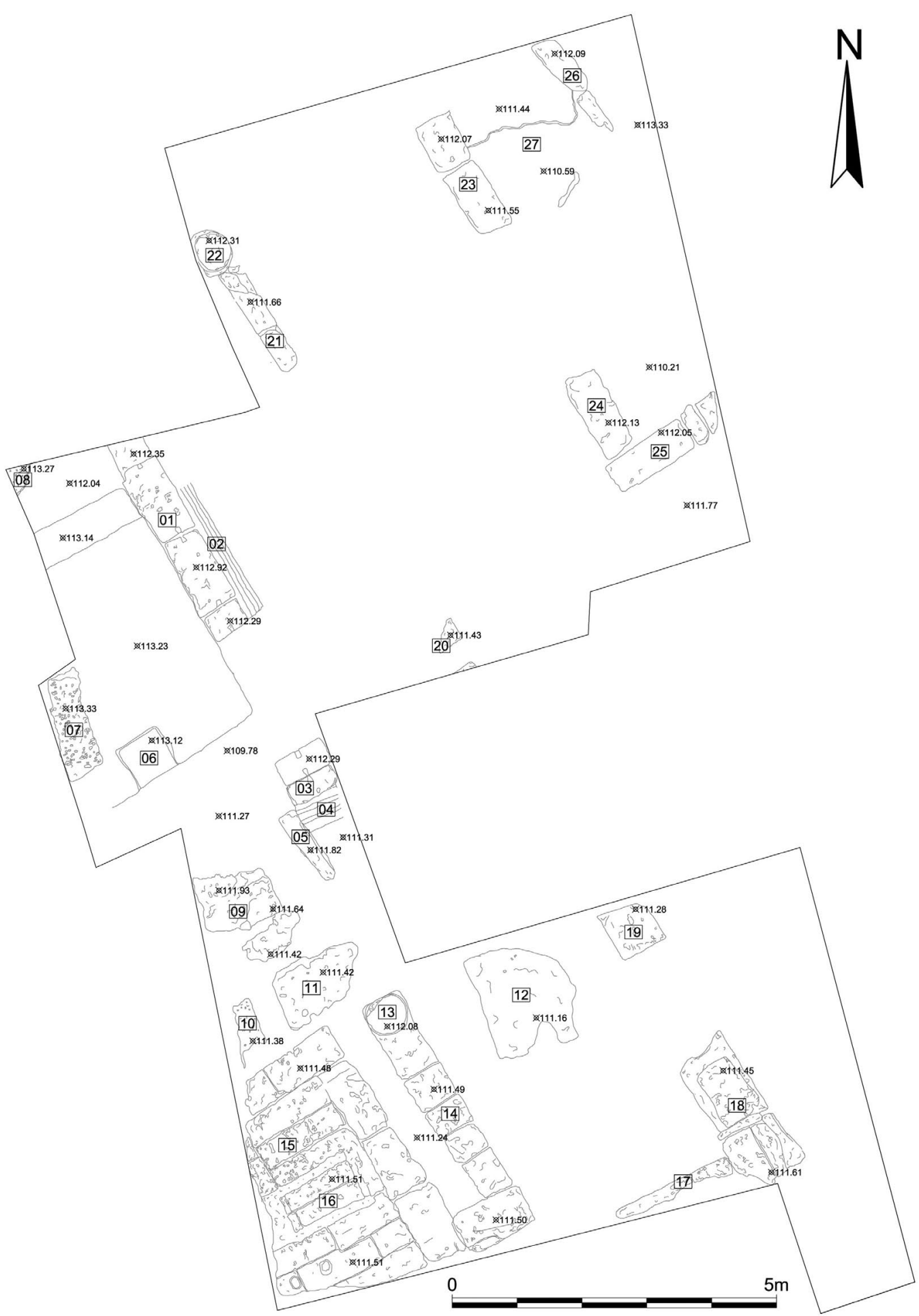

Figura 2: Planta de las estructuras adscritas a época altoimperial. Modificado a partir de Molina, 2003: plano 5.

ocupación no constituyó un hecho aislado en el caput provinciae ${ }^{5}$, donde conocemos varias estructuras intramuros adosadas a la muralla en los siglos I-II d.C. (Ruiz Bueno, 2016: 59 y 137).

5. Si en Augusta Emerita el fenómeno se detecta en el siglo I d.C. (Alba, 2001: 403), en Barcino resulta evidente desde época flavia (Beltrán, 2013: 20).
La presencia de un conjunto sacro in urbe a escasa distancia de la muralla y de una de las puertas de acceso, presenta ciertas similitudes con otros santuarios urbanos localizados en ciudades como Contributa Iulia (Mateos y Pizzo, 2015) y Tarraco (Mar et al., 2015: 328-338), puesto que en ambos casos se repite dicho esquema. Mención especial merece el santuario de la Tutela Tarraconensis, ya que también parece haberse adaptado a la orografía y al espacio disponible. Este 
último consiste en un conjunto compuesto por una pequeña plaza, dotada de un porticado en «U», y al fondo de la cual se levantó un templo con una orientación divergente.

\section{CARACTERIZACIÓN ARQUITECTÓNICA DEL COMPLEJO SACRO}

A finales del siglo I a.C. se ha fechado la erección de un complejo arquitectónico sacro compuesto por un templo sobre podio, flanqueado por un pórtico en sus extremos Este, Oeste y Sur, y un altar que vendría a situarse frente al edificio. En el pórtico oriental de este espacio fueron documentadas una serie de pequeñas estancias interpretadas como tabernae, aunque igualmente pudieron albergar otros usos, tales como estancias privadas para los menesteres del culto, del sacerdocio o almacenes. En un momento impreciso de la segunda mitad del siglo I d.C. se detecta una intervención en el recinto consistente en la reforma de la pavimentación de las estancias del pórtico oriental y del suelo que rodea tanto al podio como al espacio intermedio entre el templo y el altar ${ }^{6}$, además de la monumentalización de parte del recinto, como es el caso de la zona perimetral del altar. Pero para entender mejor su proceso constructivo, pasaremos a continuación a desglosarlo analizando cada una de sus partes (Fig. 2).

\subsection{EL TEMENOS}

Este espacio contaba con un pórtico en sus extremos oriental, occidental y meridional con galerías de $3,25 \mathrm{~m}$ de profundidad media ${ }^{7}$, del que únicamente se conservan varios tramos de los muros interior y exterior del pórtico Este (UU.EE. 18, 19, 20, 21, 23 y $24^{8}$ ) además de un fragmento del lienzo meridional, formado por un muro con orientación NE-SO ubicado en el perfil Sur (U.E. 17) correspondiente a la fase imperial del recinto. Todos ellos están compuestos por hileras de sillares de piedra arenisca de unos $50 \mathrm{~cm}$ de potencia. Como elemento arquitectónico perteneciente a la estructura del pórtico, únicamente fue documentada una basa de $56 \mathrm{~cm}$

6. Esta reforma supuso la ocultación de la pavimentación original mediante un paquete de arcillas rojas que contenía fragmentos de cerámica marmorata y T.S.G., sobre el que se dispuso el nuevo suelo (Molina, 2003: 60).

7. Se refiere al espacio transitable del pórtico sin contar el grosor de los muros que lo forman.

8. Con el fin de favorecer la lectura, hemos asignado una nueva numeración a las principales Unidades Estratigráficas (en adelante UU.EE.), individualizadas durante la I.A.U. y que aparecen recogidas en el texto. de diámetro ${ }^{9}$ con el imoscapo tallado en el mismo bloque, elaborada también en piedra arenisca (U.E. 22) (Molina, 2003: 35). Se compone de dos toros de igual desarrollo y un pequeño listel intermedio (Fig. 3). La talla es, en general, tosca, con formas muy planas, especialmente perceptibles en los toros, en los que no apreciamos los habituales perfiles redondeados de estas molduras.

Sin embargo, el hallazgo de este elemento arquitectónico es fundamental a la hora de establecer una datación aproximada, ya que la evolución estilística de estas piezas es bien conocida. Sabemos que en época republicana comienzan a introducirse ciertas modificaciones en los elementos que constituyen las basas, encaminadas fundamentalmente a dotar de contenido a la zona de separación de los toros, algo que en los primeros modelos itálicos no tenía ningún valor. En esta etapa la escocia carecía de importancia y por ello, era concebida como una simple moldura recta y estrecha de separación entre los toros, en los que recaía toda la atención. Posteriormente, a partir de época imperial temprana, la escocia comienza a tener un mayor protagonismo, expandiéndose y adquiriendo una forma parabólica debida al retranqueo del toro superior (De la Barrera, 2000: 137). Por tanto, la similar proporción de los toros será un indicativo cronológico, ya que en los ejemplares del periodo medioaugusteo y posteriores, se tiende a reducir y estrechar el toro superior otorgando un mayor desarrollo al inferior. Los modelos pre o primoaugusteos en cambio, suelen presentar un mismo desarrollo en los toros, además de carecer de plinto y de tallar en la misma pieza el imoscapo $^{10}$ (Márquez, 1998: 117).

Por consiguiente, las características morfológicas de esta basa la relacionan con la primera fase de construcción del recinto, hacia finales del siglo I a.C. De su análisis formal podríamos igualmente extraer otras consideraciones relacionadas, en este caso, con la mano de obra que ejecuta el proyecto. Los distintos talleres que acometían estas labores, acostumbraban a distribuir el trabajo de los operarios en función de la importancia y singularidad de las zonas del recinto y de las piezas, así como de la calidad técnica y experiencia de sus artesanos. Por ello, era frecuente que los espacios secundarios o poco visibles quedasen a cargo del personal menos cualificado o experimentado, recayendo en aquellos que contaban con un mayor grado de pericia técnica, el trabajo de las partes fundamentales de la construcción (Pensabene, 2013: 489-502). El

9. Esta medida corresponde a la anchura máxima de la pieza, tomada en el toro inferior.

10. En este sentido, es importante resaltar que en la primera etapa augustea el uso de basas áticas sin plinto, con toros de desarrollo similar y molduras de coronamiento y base de podio sencillas, es un hecho constatado. Ejemplo de ello son los casos del templo de Apolo in Circo y de Magna Mater en Roma. 

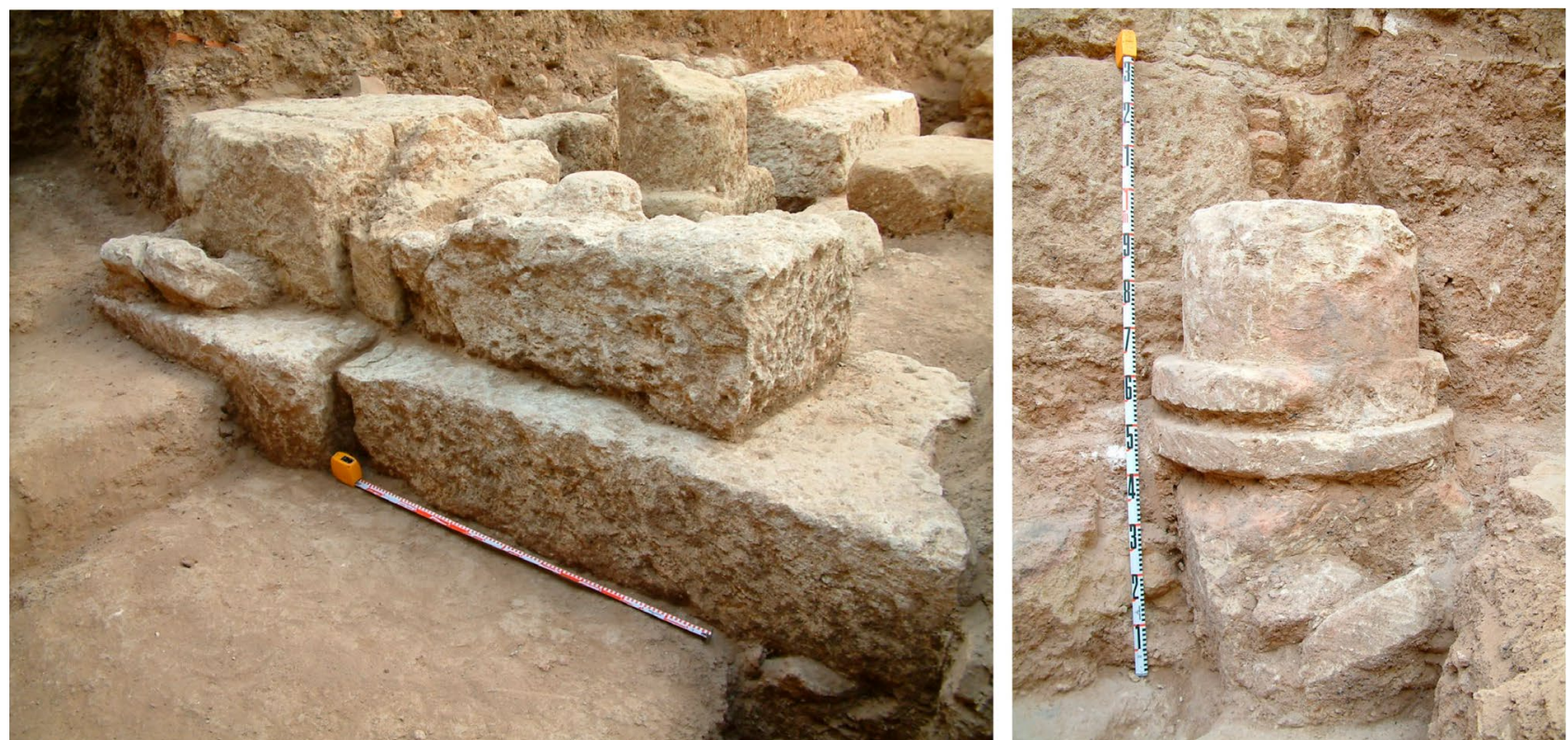

Figura 3: A la izquierda, sillares del muro del temenos (Molina, 2003: 129, lám. 41); a la derecha, basa ática sin plinto del pórtico oriental del temenos (Molina, 2003: 132, lám. 47).

aspecto rudimentario de esta basa podría estar dando muestras de este proceso, siendo quizás elaborada por algún aprendiz o principiante.

\subsection{EL TEMPLO}

El edificio principal contaba con un podium de 7,10 m de anchura (24 pedes), 14,20 de longitud (48 pedes) y $1,56 \mathrm{~m}$ de altura ${ }^{11}$ (5 pedes circa), cuyo núcleo de opus caementium quedaría envuelto por una serie de sillares de piedra arenisca unidos por grapas en forma de «cola de milano», que formarían el muro perimetral de opus quadratum (UU.EE. 1 y 3 ) (Fig. 4). Algunos de estos sillares han conservado una capa de estuco con pigmentación rojiza, correspondiente a la decoración de este edificio (Fig. 11) (Molina, 2003: 51-52).

La pronaos y cella contaban con una pavimentación de opus signinum (UU.EE. 7 y 8 ) y el acceso a las mismas se efectuaba a través de una escalera situada en el eje de la fachada del templo, realizada en opus caementicium y mortero (UU.EE. 5 y 9). Los datos extraídos de la intervención arqueológica de este edificio permiten considerarlo como un templo dístilo, próstilo e in antis con ritmo sístilo. La huella de un plinto en el pavimento de la fachada de la construcción (U.E. 6) y la inexistencia de esta marca en el ángulo SurEste de la misma, nos induce a plantearlo como un edificio dístilo, suponiendo que las antas del templo se prolongarían hasta la línea de las columnas de la

11. El podium completo, es decir, alzado y cimentación, contaría con 3,50 $\mathrm{m}$ de altura. fachada $^{12}$. Esta tipología arquitectónica carece de columnas perimetrales, por lo que lo consideramos como próstilo. El edificio contaría con dos columnas de 53,4 $\mathrm{cm}$ de diámetro (1,75 pedes) en su frente, que alcanzarían $5,33 \mathrm{~m}$ de altura (18 pedes), con intercolumnios de $1,06 \mathrm{~m}$ (3,5 pedes). En Hispania contamos con varios ejemplos de esta variante constructiva, como los casos de Mirobriga ${ }^{13}$ (Santiago do Cacém, Setúbal, Portugal), Civitas Igaeditanorum (Idanha-a-Vellha, Castelo Branco, Portugal), Asso (Cerro de la Encarnación, Caravaca de la Cruz, Murcia) o Ilici (Elche, Alicante), que demuestran el conocimiento y uso de

12. Consideramos que la anchura de la fachada $(7,10 \mathrm{~m})$, es lo suficientemente amplia como para albergar cuatro columnas y plantear así un edificio de tipo tetrástilo, tal y como su excavador advertía en el informe de la intervención. Sin embargo, la ausencia de la huella del plinto que debiera existir, en este caso, en el ángulo Sur-Este del edificio, nos hace decantarnos por la tipología dístila. Edificios tetrástilos de dimensiones similares han sido documentados dentro y fuera del territorio hispano, así destacan los ejemplos de Civitas Colbecorum (Torre de Almofara, Figueira de Castelo Rodrigo, Portugal) $(16,30 \times 8,15 \mathrm{~m})$, el templo II del foro de Pollentia (10,10 x 7,40 m) o el templo de la Plaza de las Corporaciones en Ostia (Italia) (Frade, 1990; 2010; Orfila et al., 2006: 98-99; Van Der Meer, 2009).

13. Debemos destacar la importante semejanza que existe entre el templo de la calle Tejón y Marín y el templo que preside el foro de Mirobriga, patente en su tipología y proporciones. El edificio portugués cuenta con una anchura de fachada de 7,20 m (24 pedes) y una longitud de $12 \mathrm{~m}$ (40 pedes). $\mathrm{Su}$ podio posee una altura de $1,50 \mathrm{~m}$ y la anchura de los muros de las antas de la fachada cuentan con $0,90 \mathrm{~m}$. Se trata de un edificio dístilo o pseudotetrástilo e in antis construido a mediados del siglo I d.C. (Almeida, 1964; Santos, 1998: 89-93). 


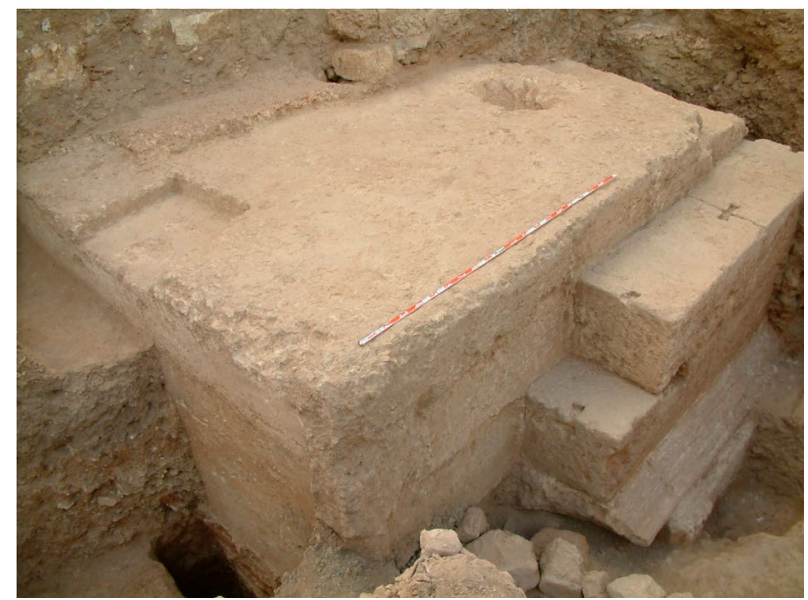

Figura 4: Podium del templo con parte de los sillares y la moldura de la base (Molina, 2003: 109, lám. 7).

esta tipología arquitectónica en este territorio (Burgholzer, 1994).

En relación a los elementos arquitectónicos que conformarían este edificio, únicamente se ha conservado la moldura que decoraría la base del podium, elaborada en piedra arenisca y recubierta con mortero (UU.EE. 2 y 4). Esta se compone de una cyma recta seguida de dos boceles que enmarcan un caveto, con los que se remata la moldura en su zona superior. Se trata de una pieza fundamental en el estudio de este edificio, ya que constituye uno de los pocos elementos útiles para datar la construcción, además de ser imprescindible para poder relacionarla con otros modelos arquitectónicos. Entre los paralelos morfológicamente más cercanos a esta moldura, destacan los ejemplos de las bases de podio de varios edificios augusteos tales como el templo de Divo Iulio y el templo Norte del foro Holitorio, en Roma y de algunas tumbas de Ostia como el Mausoleo de Porta Marina (Fig. 5). En todos estos casos encontramos como característica común, una articulación y desarrollo de las molduras

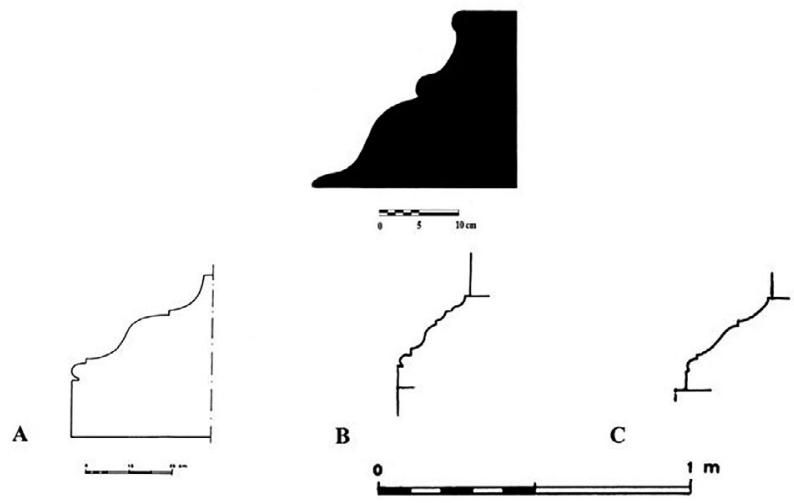

Figura 5: Sección de molduras de base de podio. Arriba, Templo c. Tejón y Marín, 14. Córdoba (finales del siglo I a.C.). Abajo: A. Templo Norte del Foro Holitorio, Roma (época augustea). B. Templo del Divo Iulio, Roma (época augustea, 29 a. C.). C. Mausoleo de Porta Marina, Ostia (época augustea). Modificado a partir de Crozzoli, 1981: 94, fig. 126 y 109, fig.137, nº 4 y 14. muy parecida. Se trata de composiciones sencillas, en las que tanto la cyma como el resto de componentes, ocupan una superficie muy similar en proporciones, no destacando de forma evidente, ninguna de sus partes integrantes. Esta tendencia se irá modificando paulatinamente a medida que avance la primera centuria de nuestra Era, a favor de un mayor desarrollo de cyma, la cual irá adquiriendo un acusado protagonismo a partir de la construcción del templo de Mars Ultor en el foro de Augusto en Roma (Gros, 2001: 134).

\subsection{EL ALTAR}

Frente al templo y alineada con la fachada del mismo, aunque separada de él por un pavimento de mortero (U.E. 10), se construyó una plataforma rectangular de sillería de 3,88 $\mathrm{m}$ de anchura y 4,18 $\mathrm{m}$ de longitud (U.E. 15), en cuyo centro se levantó un ara de $1,30 \mathrm{~m}$ por $0,86 \mathrm{~m}$ (U.E. 16). En el extremo Norte del altar encontramos una rampa que daría acceso a este espacio y junto a ella, se ha conservado la huella de los canceles que cerrarían este pequeño recinto (Fig. 6). Al Este del altar y paralelo al mismo, se encuentran una hilera de sillares de piedra arenisca (U.E. 14) que presentan un módulo distinto al empleado en el resto del recinto, en cuyo extremo Norte apareció in situ una basa de columna de $63 \mathrm{~cm}$ de diámetro ${ }^{14}$ y $60 \mathrm{~cm}$ de altura, de tipo ática, sin plinto y con el imoscapo tallado en el mismo bloque, elaborada en caliza micrítica gris (U.E. 13) (Molina, 2003: 53) (Fig. 6).

Este modelo de basa puede fecharse a partir de los primeros momentos del periodo augusteo, aunque hemos de tener en cuenta que su uso en el territorio hispano se prolongará en el tiempo hasta los comienzos del periodo flavio (Borrego y Felipe 2014: 100, nota 2). Para intentar establecer una correcta datación, debemos realizar una serie de observaciones que se relacionan tanto con la morfología de la pieza como con la naturaleza del material en el que se encuentra elaborada.

Por una parte, el uso del plinto no se generalizará hasta época medioaugustea como podemos observar en muchas construcciones de este momento ${ }^{15}$. Este hecho es también constatable en numerosos edificios peninsulares datados en época augustea, donde aparecen este mismo tipo de basas aún sin plinto ${ }^{16}$ (Márquez, 1998: 116).

Por otro lado, podemos establecer una cronología aproximada a través del propio material, ya que es precisamente en el tránsito de la etapa tardorrepublicana

14. Esta medida correspondería al diámetro del toro inferior, siendo el diámetro del imoscapo de $0,51 \mathrm{~m}$.

15. Entre ellas podemos citar el foro de Augusto, la basílica Aemilia o el templo de Apolo Sosiano, todos ellos en Roma.

16. Como en los casos del templo de Barcino (Barcelona), el «templo de Diana» en Augusta Emerita (Mérida) o el templo de Évora en Portugal. 

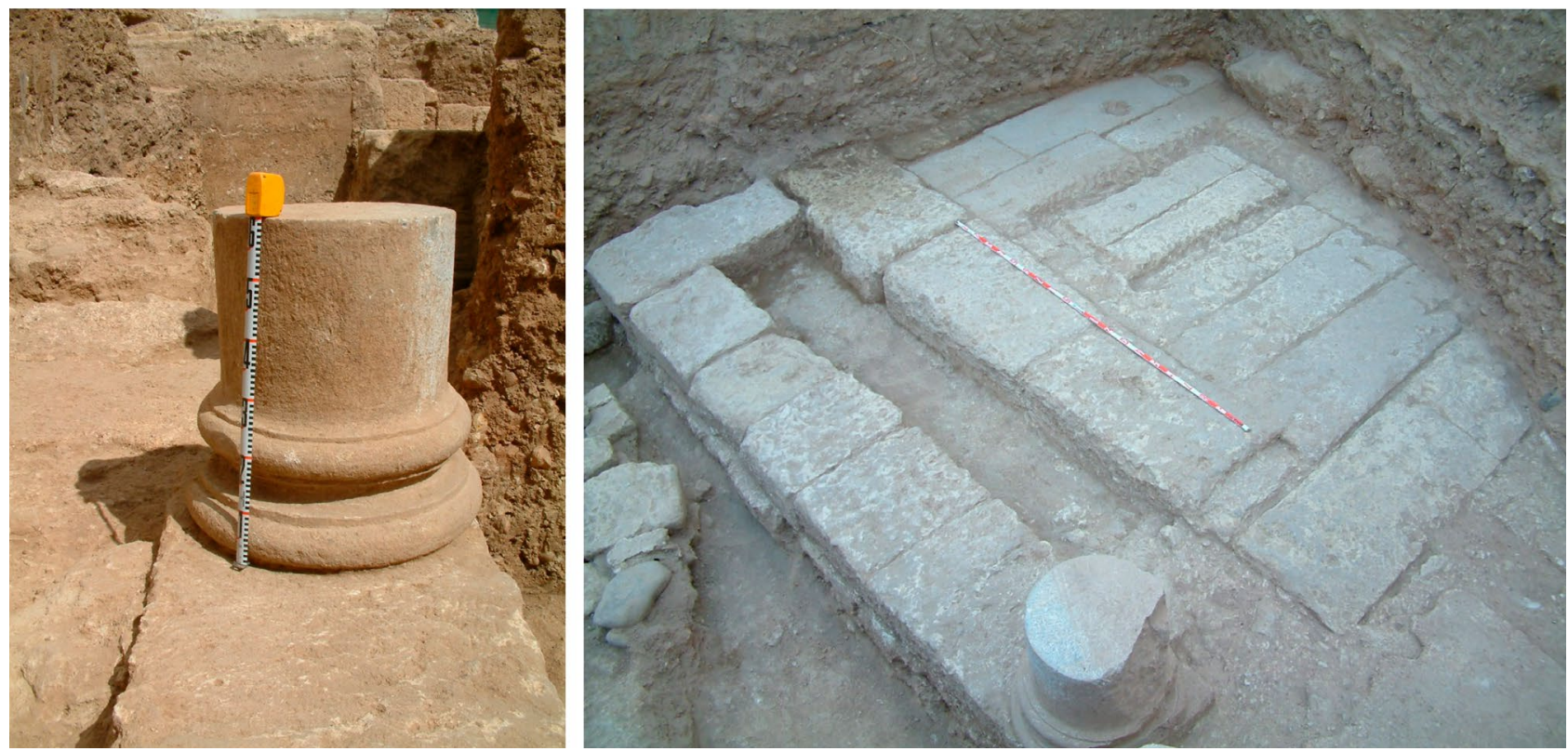

Figura 6: A la izquierda, basa ática sin plinto de la zona contigua al altar (Molina, 2003: 125, lám. 35); a la derecha, altar del recinto con huella del ara en el centro (Molina, 2003: 126, lám. 37).

a la augustea cuando ha sido documentado en $\mathrm{Co}$ lonia Patricia, el empleo de este nuevo material de origen local, la conocida como «piedra de mina», una caliza micrítica de la formación Linares-Pedroches del cámbrico cordobés que será empleada en la ciudad durante buena parte del periodo imperial (Gutiérrez, 2012: 302). La acusada dureza de este material y por consiguiente, la complejidad de su talla, haría necesaria la progresiva especialización de los talleres locales en el trabajo de estas rocas duras, hasta alcanzar un importante grado de pericia técnica, como así lo demuestran los distintos testimonios arqueológicos hallados en la ciudad ${ }^{17}$. Esta basa presenta una talla más cuidada y mayores dimensiones que la hallada en el temenos, una circunstancia que explicaría el trabajo de manos experimentadas en los elementos principales del complejo, dejando la producción de piezas elaboradas en rocas más dúctiles y fáciles de modelar, destinadas a ocupar zonas secundarias o menores, a aprendices u operarios del taller con menor grado de cualificación.

El acceso a este recinto sacro se realizaría por su extremo Sur, probablemente, a través de una entrada ubicada en el eje del altar situada en el muro exterior del complejo. Hemos desestimado aquí cualquier tipo de cubrición de la zona del ara, con la que podrían relacionarse estos elementos, pues este hecho no cumpliría con los requerimientos básicos de la ritualidad

17. Entre ellos cabe destacar el enlosado del foro colonial, el grupo de basas halladas en la calle Braulio Laportilla (pertenecientes a una construcción vinculada al forum coloniae) o el rostrum o proa de nave recuperada en el barrio de San Lorenzo (Godoy, 1996; Almoguera, 2011: 41-48; Gutiérrez, 2012). romana, interfiriendo así en la práctica y desarrollo de las ceremonias, en la que se establece como norma la carencia de techumbre de este receptáculo. La necesidad de estar en contacto visual con la esfera celeste (lugar donde habitaban los dioses), se perfilaba como uno de los elementos intervinientes directos en la configuración de estos espacios. Las ofrendas, de incienso en primer lugar para la invocación de las divinidades, y más tarde libaciones (de vino, leche, miel, etc.), u oblaciones de frutos o victimas animales, debían simbólicamente ascender hasta el cielo, donde eran recibidas por las deidades. Esta circunstancia inhabilita, a nuestro parecer, la existencia de algún tipo de cubierta en el altar ${ }^{18}$.

Es importante destacar que esta zona del recinto presenta una complejidad interpretativa que intentaremos resolver en la medida de lo posible, ya que este sector coincide con el límite de uno de los cortes de la intervención arqueológica, hecho que dificulta el entendimiento de las relaciones arquitectónicas existentes entre determinadas estructuras. Algunas de ellas establecen vínculos coherentes entre sí, como en el caso de los muros de los pórticos laterales o el altar, donde observamos el empleo de un módulo idéntico o similar en la sillería y una correspondencia funcional, otras en cambio, como el muro paralelo al altar en su extremo oriental (U.E. 14), presenta una modulación distinta con sillares de diferentes proporciones que nos hacen contemplarlos como pertenecientes a una fase posterior a la primitiva o de erección del primer complejo. El hallazgo de la basa de columna de piedra de mina

18. En relación a la posible existencia de altares con cubierta, debemos destacar aquí que no se conoce, hoy por hoy, ningún ejemplo de ello en todo el territorio romanizado. 


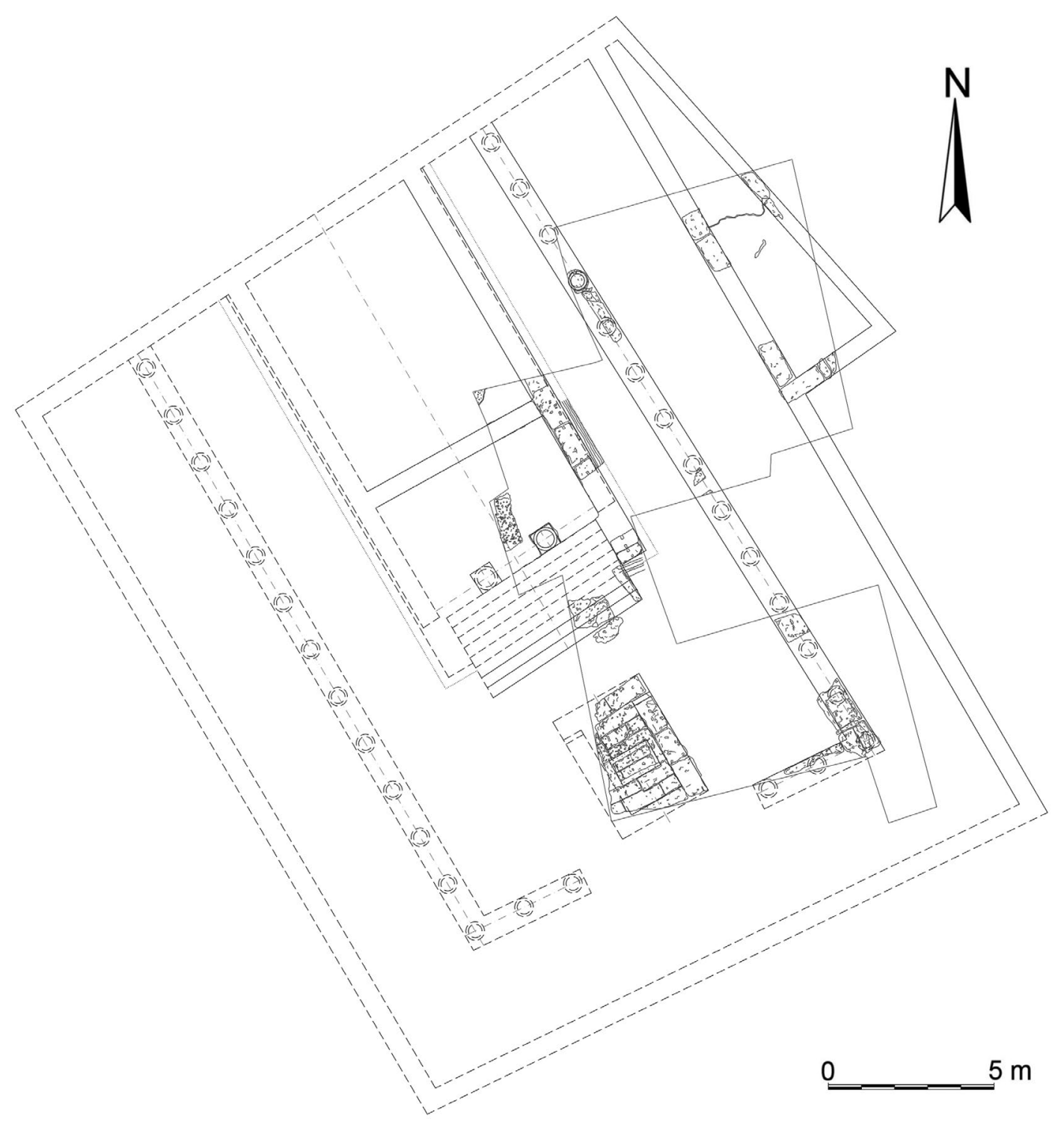

Figura 7: Planta del recinto sacro en la fase 1 (finales del siglo I a.C.). Modificado a partir de Molina, 2003: plano 5.

en el ángulo noreste de este muro, nos hace plantear la existencia de una segunda basa en el extremo opuesto. Teniendo en cuenta que se trata de un tipo de basa morfológica, material y proporcionalmente distinta a la hallada en los pórticos laterales (U.E. 22), su empleo aquí resulta difícil de precisar. Hemos invalidado anteriormente su relación con cualquier tipo de cubierta del altar, sin que pueda pertenecer tampoco a la zona de los pórticos, ya que no concuerda ni en forma ni en formato. Por lo tanto, únicamente podemos vincularla a una hipotética estructura monumental que rodearía el sector del altar, quizás soportando algún tipo de friso ornamental o inscripción dedicatoria, sin que ello inhabilite otras posibles interpretaciones ${ }^{19}$. Creemos,

19. Es importante subrayar el carácter hipotético de esta acción de monumentalización del sector del altar, ya que a partir del análisis de los datos disponibles, no hemos hallado una por consiguiente, que esta sería una explicación plausible a la problemática que aquí se plantea, obteniendo en definitiva, la siguiente secuencia constructiva:

- Fase 1 (finales del s. I a.C.): erección del templo, el altar, los pórticos y las estancias o tabernae (Fig. 7).

- Fase 2 (segunda mitad del s. I d.C.): renovación de algunos componentes del anterior recinto tales como el pavimento de algunas zonas del complejo y construcción de una estructura monumental que rodearía el área del altar (Fig. 8).

respuesta más acertada que explique la presencia de este muro paralelo al recinto del altar y de la basa de piedra de mina. 


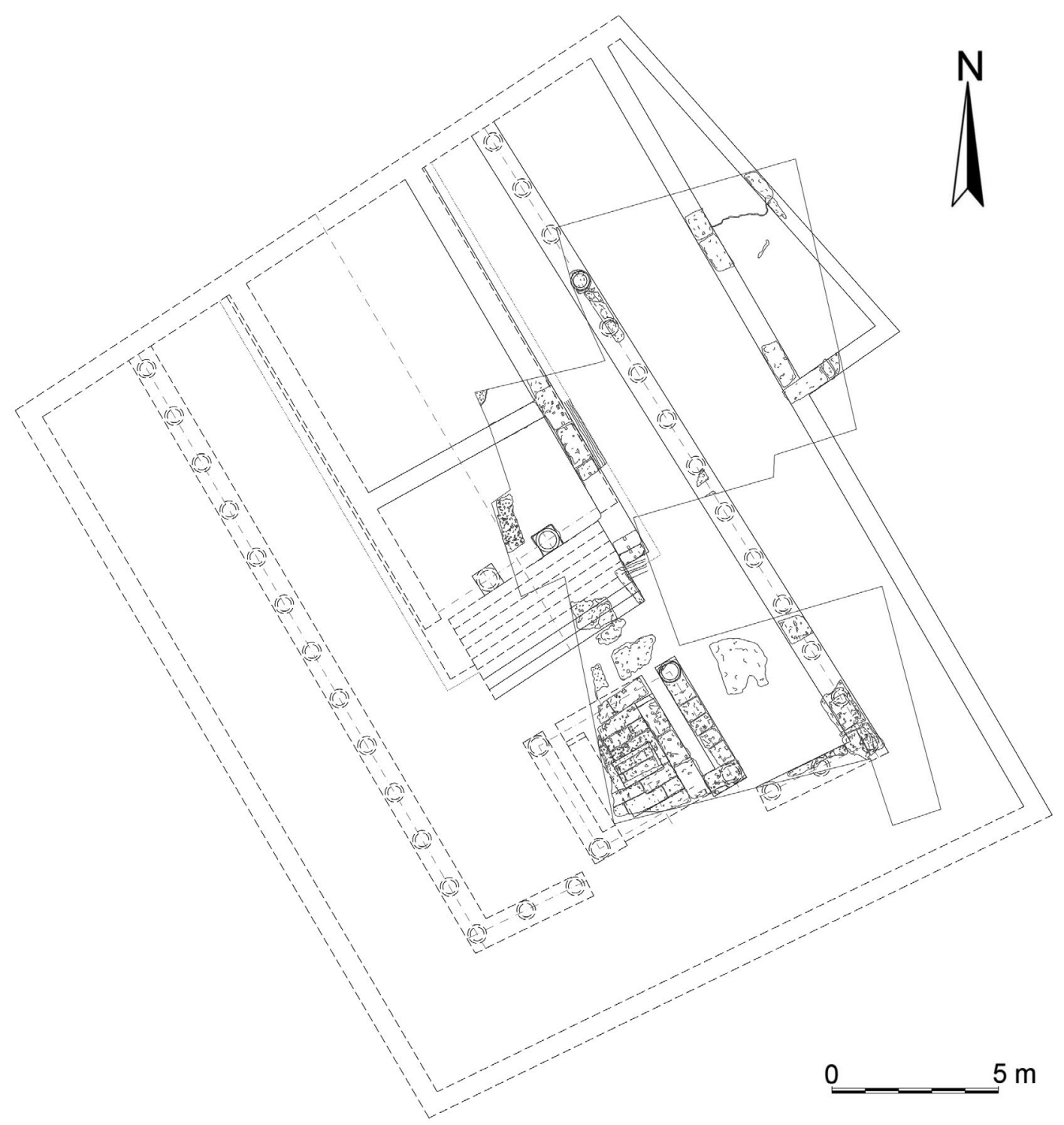

Figura 8: Planta del recinto sacro en la fase 2 (segunda mitad del siglo I d.C.). Modificado a partir de Molina, 2003: plano 5.

\section{ABANDONO Y POSTERIOR REOCUPACIÓN DEL CONJUNTO}

La inutilización del complejo cultual de la c. Tejón y Marín debió de acaecer hacia el siglo $\mathrm{IV}^{20}$, cuando dio comienzo un proceso de saqueo tras el cual la mayor parte de las estructuras quedaron parcial o totalmente

20. «Los niveles de amortización de la zona del ara y de la escalinata de acceso, además de otro estrato que se entrega a la sillería que rodea al podium (lado este), presentan arcillas rojas con sillares de arenisca derrumbados, fragmentos de tegulae, cerámicas T.S.G., claras africanas (es decir, T.S.A.) y africanas de cocina, puede indicarnos un uso sacro hasta el siglo IV». (Molina, 2003: 60). Esta datación se basa también en el terminus ante quem que proporciona la cronología (ss. IV-V) tanto de una tumba practicada entre el templo y el recinto del ara, como de varias estructuras aisladas levantadas en el antiguo temenos. ocultas bajo distintos niveles arcillosos con una potencia variable (alrededor de $60 \mathrm{~cm}$ de media). Tales estratos contenían todo tipo de materiales constructivos (sillares fragmentados y completos, tegulae, ladrillos y fragmentos de opus signinum), pero también carbones, restos óseos animales, vidrio o cerámica (Molina, 2003: 11 ss.).

En el estado actual de la investigación, la desaparición de la arquitectura sacra característica de Colonia Patricia pudo comenzar en las últimas décadas del siglo III y proseguir en la cuarta centuria. A la ruina de un complejo cultual anexo al teatro hacia los años 50-60 del siglo III, hay que sumar el destino de los templos que presidían tanto el complejo de la c. Capitulares (el templo podría estar ya destruido hacia finales del III - principios del IV, mientras que los pórticos aledaños estaban siendo saqueados a inicios del IV), como el forum novum (la plaza y el templo ya estaban siendo desmantelados a finales del III - inicios del 
IV). Algo más tardía es la inutilización del complejo sacro de los Altos de Santa Ana, ocupado por estructuras domésticas con posterioridad al primer cuarto del siglo IV (Ruiz Bueno, 2016: 574-576 y 587-588).

A una escala supralocal, el siglo III se caracterizó por un descenso en la construcción de nuevos templa en regiones como el Norte de África, Asia Menor y la propia Roma, donde solo se inauguraron unos pocos en dicha centuria. Este fenómeno apunta hacia un menor interés por la arquitectura religiosa y a un cambio en las prioridades edilicias, evidente ya durante la dinastía severiana y que continuó en época tetrárquica, cuando la tónica general fue la reparación de los edificios preexistentes (Lavan, 2011: 42-43). Asimismo, desde al menos la tercera centuria, los sacrificios perdieron peso e importancia a favor de otras prácticas menos sangrientas ${ }^{21}$. Estos antecedentes podrían explicar el escaso número de inscripciones relativas a la construcción y restauración de templos urbanos ya en época de Constantino (López Quiroga y Martínez, 2006: 131), cuya política antipagana quedó limitada en gran medida a una destrucción selectiva (y por orden suya) de determinados templos situados en el Levante mediterráneo que resultaban especialmente ofensivos para los cristianos, o en los que tenían lugar actividades inmorales (Fernández, 2009: 88-89). Esta decisión no se extendió a Hispania, donde los cánones del concilio de Elvira ( $\mathrm{ca}$.303-305) no solo omiten cualquier alusión a los templos, sino que prohíben la destrucción de estatuas e ídolos paganos por iniciativa propia (Arce, 2006: 121).

Más determinante fue el impacto de la religio christiana en la arquitectura cultual desde los años 40 del siglo IV. La llegada al poder de los hijos de Constantino supuso el arranque de una creciente legislación antipagana que, tras interrumpirse brevemente durante el gobierno de Juliano, recibió un impulso definitivo durante la dinastía teodosiana. El resultado de este corpus de normas cada vez más estrictas ${ }^{22}$ fue «a widespread closure of urban temples» (Lavan, 2011: 35) pero sin que ello implicase su destrucción generalizada, al tratarse de edificios de carácter polifuncional con un importante valor estético, histórico y político (Arce, 2006: 118; Foschia, 2009: 215). Como resultado, «there was at no time a general policy of the Church or state that actually permitted undue acts of aggression against temples» (Bayliss: 2001, 49).

21. L. Lavan (2011: 47) considera possible «that there was an underlying long-term decline of the importance of urban temples within the paganism, which was connected to alienation from their principal rite. In this perspective, the disuse and even closure of temples could be seen as the final chapter in a longer story, which had little to do with Christianisation».

22. Sobre dichas leyes, véanse las contribuciones de Bayliss, 2001: 31 ss.; Caseau, 2001: 70 ss.; Arce, 2006: 116 ss.; López Quiroga y Martínez, 2006: 130 ss.; Foschia, 2009: 210 ss.; Lavan, 2011: 22-23.
Las principales excepciones a dicho panorama proceden del Levante mediterráneo, donde la conjunción de «un evêque zélé, de moines et d'un membre de l'administration au moins complasaint parfois directamente impliqué» (Caseau, 2001: 92), supuso la destrucción violenta de determinados templos a finales del siglo IV e inicios del V (Lavan, 2011: 39-40). Por el contrario, la inutilización de los templa en el resto del Imperio se trató, salvo excepciones, de un proceso paulatino y no traumático ${ }^{23}$, de modo que «temples were closed and a few were desecrated, though most were ignored and left to rot, if an inmediate pragmatic use could not be found》 (Lavan, 2011: 36). Esta imagen es extensible a la península ibérica, donde «no tenemos constancia de destrucción o arrasamiento de los templos paganos» por parte de las autoridades cristianas, ya que quizás «el cristianismo hispánico, que se desarrolló muy lentamente, fue más tolerante que en otros lugares》 (Arce, 2006: 117 y 124).

La amortización del complejo cultual de la c. Tejón y Marín en el siglo IV debió de ser coetánea a la destrucción de otros templos hispanorromanos como el que encabezaba el foro colonial de Astigi, derrumbado parcialmente a mediados del siglo IV (GarcíaDils, 2015: 239; García-Dils et al., 2007: 98), o el Traianeum de Italica, cuya destrucción pudo haber acontecido hacia el siglo IV (Verdugo, 2003: 372373). Si exceptuamos algunos templos que permanecieron en pie hasta fechas más avanzadas, como los que presidían el «foro provincial» de Augusta Emerita, destruido en el siglo V (Alba y Mateos, 2006: 356-364) o el forum provinciae de Tarraco, desmantelado a finales del siglo V - inicios del VI (Macias, 2014: 459), la principal excepción procede de Complutum. Las últimas excavaciones han atestiguado la construcción, entre 340 y 380 d.C., de un pequeño templo (con una cella de 4 por $4 \mathrm{~m}$ en planta) relacionado con el culto imperial (Rascón y Sánchez, 2015: 207-208).

Una vez que finalizó el saqueo a gran escala del recinto cultual cordobés de c. Tejón y Marín 14, dicho espacio adquirió en los siglos IV-V una funcionalidad tanto funeraria, como presumiblemente doméstica y/o productiva (Fig. 9). Así, uno de los estratos que cubrió tanto el pavimento situado entre el templo y el recinto del altar, como el hueco dejado tras la sustracción de algunos sillares de la escalinata, fue horadado por una fosa simple cubierta por cuatro tegulae dispuestas en

23. De los más de 700 templos documentados en la Galia, solo hay evidencias de destrucción violenta en unos diecisiete $(2,4 \%)$. No obstante «distinguishing between Christian iconoclasm and the effects of accidents, barbarian invaders, economically motivated plundering or indeed solicitous pagans seeking to hide their own religious statuary, is often impossible» (Goodman, 2011: 178). En el Norte de África «the archaeological evidence for the use of violence to destroy pagan sacred places is relatively uncommon»» (Sears, 2011: 243). 
horizontal y que contenía un adulto ${ }^{24}$ (Molina, 2003: 44-48). Se trata de una tumba (U.E. 28) que pudo haber formado parte de un área cementerial mayor al haberse recuperado restos óseos humanos en el interior de pozos negros islámicos, por lo que "podemos decir que al menos hubo tres inhumaciones» (Molina, 2003: 54).

En los siglos IV-V también se ha datado la erección de varias estructuras aisladas que incluyen un nivel de picadura de sillar compacto (de 1,20 por $1,48 \mathrm{~m}$ ) relacionado con un suelo (U.E. 29); la cimentación o alzado de un muro (de 0,70 $\mathrm{m}$ de ancho) a base de sillares de arenisca y que se entregaba por su extremo Oeste al antiguo podium (U.E. 30); un segundo paramento con una anchura similar y del que se conservaban dos hiladas de sillares de arenisca (U.E. 31), y por último, un pequeño murete del que solo se conservaba una hilada (U.E. 32) y que ha sido puesto en relación con un suelo de ladrillos (Molina, 2003: 11 ss. y 54).

Tras la amortización y cubrición de las estructuras precedentes, ha podido fecharse la construcción de dos nuevos ambientes adscritos a los siglos V-VI. El más meridional presentaba un pavimento a base de mortero (UU.EE. 33 y 34), mientras que el más septentrional estaba delimitado mediante muros (de 0,50 $0,60 \mathrm{~m}$ de anchura media) con cimentación a base de cantos de río unidos con mortero, y alzado consistente en una o dos hiladas de sillares de arenisca de diferentes medidas (UU.EE. 35, 36 y 37) (Molina, 2003: 11 ss. y 55).

Desde un punto de vista funcional, A. Molina (2003: 63) ha sugerido que las distintas estructuras tuviesen una finalidad doméstica. Por el contrario, para I. Sánchez (2010: 39) la detección tanto de dichas estructuras, como de al menos una tumba de los siglos IV-V podría reflejar «una teórica sacralización del lugar». Aun cuando esta última posibilidad es una hipótesis sugerente, la limitada documentación disponible invita a la prudencia ya que la presencia de tumbas en un antiguo edificio sacro pagano no implica necesariamente la existencia de una iglesia cercana. No olvidemos que la construcción de iglesias sobre antiguos templa fue un fenómeno minoritario (por lo general, detectado a partir de finales del siglo $\mathrm{V}$ en adelante $^{25}$ ), y que la instalación de necrópolis sobre

24. Un individuo dispuesto en decúbito supino, con el brazo izquierdo sobre la pelvis, el derecho extendido a lo largo del cuerpo y las piernas giradas hacia la derecha con una ligera flexión de las rodillas. La sepultura contenía también un broche o remache de bronce, dos clavos de hierro (uno en la zona del cráneo y otro próximo a la rótula de la pierna izquierda) y restos de fauna (valvas de ostreidos y de un gasterópodo, dos mandíbulas de cabra u oveja próximas al pubis y un diente de jabalí) puestos en relación con banquetes rituales post mortem (Molina, 2003: 47).

25. A lo largo y ancho del Imperio Romano se conocen con seguridad unos ciento veinte templos reconvertidos en iglesias, de los cuales solo un tercio sufrieron dicha transformación antiguos templos no implica necesariamente la existencia de una ecclesia aledaña. Valga como ejemplo la documentación arqueológica procedente de la Ga$1 \mathrm{lia}^{26}$, pero también de ciudades hispanas como Carteia $^{27}$, Conimbriga ${ }^{28}$ y Valentia ${ }^{29}$, no siempre exenta de polémica.

En principio, la hipótesis que nos parece más factible es que en c. Tejón y Marín 14 nos encontremos ante varias construcciones de carácter residencial y/o productivo cuyos moradores pudieron ser enterrados en el entorno inmediato. Tradicionalmente, las tumbas intramuros no vinculadas a edificios sacros han sido interpretadas como enterramientos «aislados» ubicados en zonas abandonadas y que acogieron a individuos excluidos de la comunidad desde un punto de vista social y/o religioso. No obstante, en la actualidad se aboga por ponerlos en relación con «establecimientos residenciales-productivos con su propia

con anterioridad a finales del siglo V (Lavan, 2011: 24). En la propia Roma o en el Mediterráneo Oriental, «fear of the dark spiritual power hidden in temples and within idols persisted, and seems to have prevented temples being converted until the late 5th c. or later» (Sears, 2011: 254). En Hispania recientemente se ha propuesto la existencia, con anterioridad a 414-415, de una iglesia levantada en el espacio intramuros de Barcino, y de manera más concreta, sobre un emplazamiento ocupado en época altoimperial por un posible templo y un castellum aquae/depósito aledaño (Beltrán, 2013: 24-31; 2015: 138 ss.).

26. Hasta la fecha conocemos trece templos céltico-galorromanos que tras su abandono fueron ocupados por sepulturas «but the point should be made that the installation of a church was not inevitable. The temple of Tronche-Bélon at Riaz in Switzerland became the focus of a cemetery after its abandonment in the early 4th c., but no church is known here. At least nine temples saw domestic (re)occupation, usually in the form of hearths or lean-to structures» (Goodman, 2011: 186).

27. En la ciudad bética conocemos una posible iglesia instalada sobre la cella oriental y central de un antiguo templo republicano inutilizado en fechas tan precoces como finales del siglo I a.C. (Bernal, 2006: 431; Roldán et al. 2006: 390). Sobre el templo y sus inmediaciones se dispuso un área cementerial fechada en un momento avanzado del siglo VI (Bernal, 2006: 453, 461-463).

28. En Conimbriga se ha propuesto la existencia de un espacio cristiano levantado sobre el foro (templo incluido) al que pertenecerían varias inhumaciones datadas desde el siglo IV en adelante (De Man, 2005: 45). Esta cronología y funcionalidad han sido matizadas por J. López (2013: 327), quien considera que «carecemos de elementos arqueológicos, como venimos insistiendo de forma reiterada, para sustentar la idea de una cristianización del templo del foro en una fecha tan temprana como el siglo $I V »$, por lo que el debate sigue abierto.

29. En Valencia ha sido identificada una necrópolis instalada en la segunda mitad del siglo IV en el temenos de un posible santuario suburbano «lo que indicaría la conversión del edificio al culto cristiano» (Alapont y Ribera, 2009: 60). No obstante, la arqueología no ha probado su uso como inmueble sacro cristiano (Arnau et al., 2005: 261). 


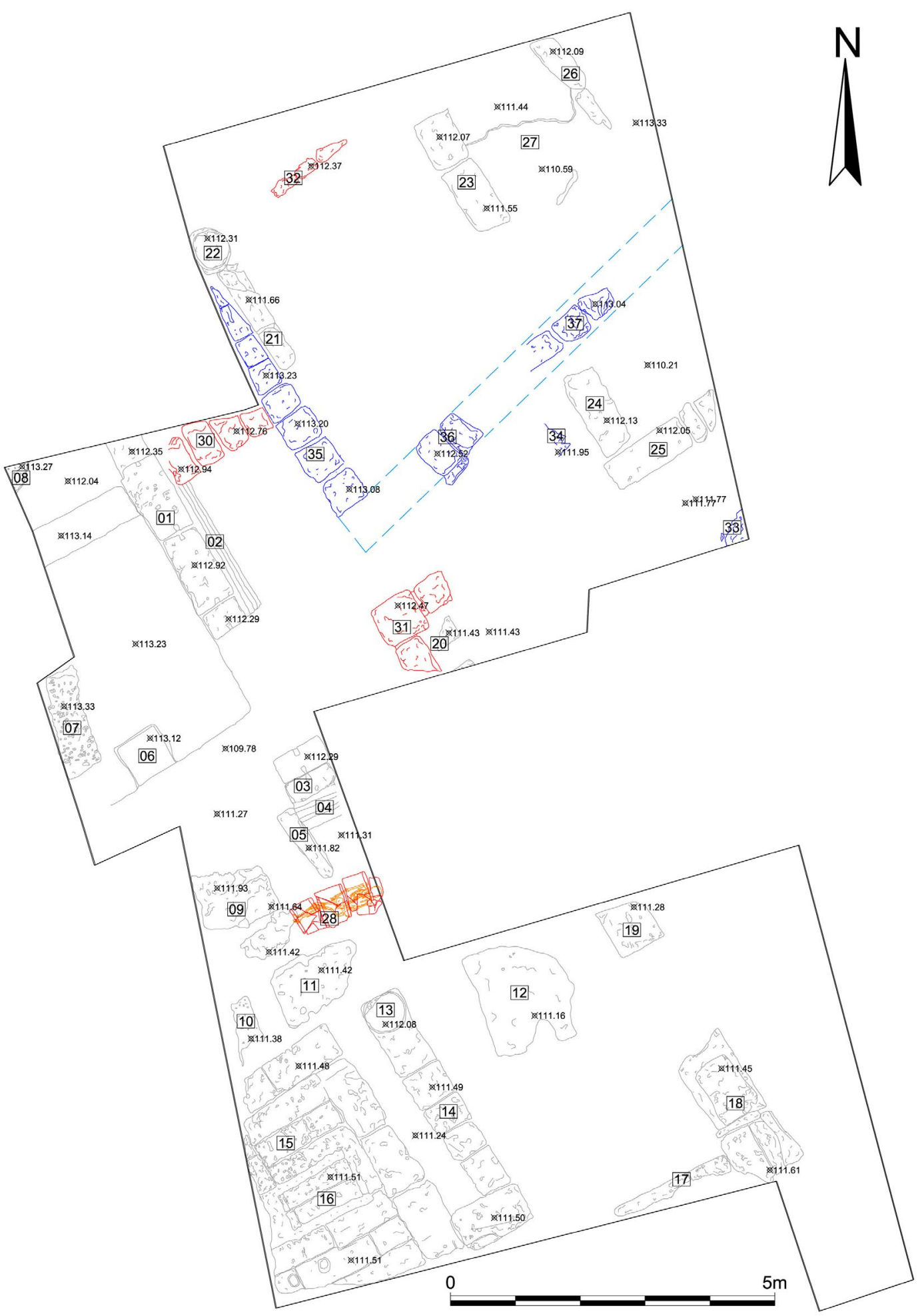

Figura 9: Planta combinada de las estructuras adscritas a época altoimperial y a los siglos IV-VI. Modificado a partir de Molina, 2003: planos 5,6 y 7 .

necrópolis» (Azkarate, 2002: 129). Esta modalidad de enterramiento ha podido ser bien identificada en el norte de Italia, donde conocemos varias áreas cementeriales compuestas por un número variable de tumbas (entre siete y diez) que contenían individuos infantiles y adultos de ambos sexos. Por el contrario, las escasas sepulturas hispanas adscritas con seguridad a esta categoría consisten, a grandes rasgos, en enterramientos puntuales y de carácter infantil (Ruiz Bueno, 2017: 30). Entre las excepciones tenemos una necrópolis instalada en el vetusto teatro de Colonia Patricia y su entorno inmediato, donde ha podido 
detectarse la coexistencia en el siglo VII de un barrio residencial y de un área cementerial aledaña compuesta por al menos cuatro inhumaciones (Monterroso y Cepillo, 2002: 163-166; Ventura, 2000; Sánchez, 2006: 401). Se trata de un esquema que, con las cautelas necesarias y a falta de futuras excavaciones, pudo repetirse en el antiguo complejo cultual de la c. Tejón y Marín 14.

\section{CONCLUSIONES}

El análisis de los elementos integrantes del conjunto sacro de c. Tejón y Marín 14 merece una valoración más pausada que nos permita desentrañar algunos problemas estructurales y estilísticos que han derivado de su estudio, así como reflexionar acerca de cuestiones tan importantes como la funcionalidad o titularidad del complejo. En primer lugar, cabría destacar la evidencia de distintos momentos o fases dentro del proceso constructivo del recinto. Este hecho ha quedado de relevancia con la erección de un primer espacio, a finales del siglo I a.C., cuyos elementos fundamentales parecen haber sido el templo, el altar y los pórticos con sus respectivas estancias. En todos ellos encontramos una coherencia arquitectónica compartida tanto en las formas, como en los módulos y el material constructivo empleado, lo que apela a la pertenencia a un proyecto inicial y unitario.

A un segundo momento más avanzado en el tiempo, hacia la segunda mitad del siglo I d.C., parecen responder algunas de las estructuras documentadas en esta intervención, tales como algunos pavimentos puntualmente reformados y, sobre todo, la línea de sillares contigua al altar, sobre la que se halló la basa de piedra de mina. En este caso llama nuestra atención el empleo de un módulo distinto en los sillares de arenisca, además de tratarse de una estructura cuya funcionalidad resulta compleja de dilucidar dada su situación en el solar. Su imposibilidad como parte de una estructura que cubriese el altar y las diferencias dimensionales, materiales y formales de la basa respecto a la hallada en los pórticos, plantean la posibilidad de que estos elementos respondiesen a una fase constructiva distinta, quizás a una renovación del viejo recinto cuya finalidad habría sido monumentalizar el sector Sur del complejo, otorgando una mayor relevancia al recinto del altar y a la zona de la entrada en definitiva.

Igualmente, la existencia de la huella de un plinto en la fachada principal del templo, resulta un hecho importante que podría estar indicando la sustitución de algunos de los elementos arquitectónicos del edificio en una fase posterior. Como ya hemos citado anteriormente, el empleo de basas con plinto de forma sistemática no se hará efectivo hasta el periodo medioaugusteo, pudiéndose comprobar cómo muchos de los edificios augusteos construidos en la península ibérica no cuentan con este elemento ${ }^{30}$ (Márquez, 1998: 116). Esto nos lleva a plantear dos cuestiones distintas para explicar la presencia de esta huella: o bien la construcción del edificio se prolongó lo suficiente en el tiempo para llegar a incorporar el plinto a las columnas de la fachada, dentro del proceso evolutivo natural y la anexión de innovaciones estilísticas en el marco general de la arquitectura romana; o dichos plintos pertenecen a una fase distinta a la primitiva, ésta más avanzada en el tiempo ${ }^{31}$, en la que ya habrían quedado plenamente establecidos los modelos canónicos generados en la arquitectura augustea, habiéndose difundido a las provincias como habitualmente sucede con las innovaciones edilicias. En relación a estos materiales, debemos llamar la atención sobre un aspecto que resulta fundamental para la interpretación de la tipología arquitectónica del edificio principal.

En primer lugar, resulta llamativa la similitud dimensional existente entre la columna hallada en el perímetro del altar y las que se ubicarían en la fachada del templo. Ambas contarían con imoscapos de unos 51 a $53 \mathrm{~cm}$. Este hecho sumado a la diferencia tipológica existente entre ellas ${ }^{32}$, nos hizo pensar en un primer momento, en la posibilidad de que las columnas ubicadas en el entorno del altar pudieran haber pertenecido originalmente a la fachada del templo, siendo reaprovechadas posteriormente (hacia la segunda mitad del siglo I d. C.), para la supuesta monumentalización del recinto del altar. Dicha propuesta implicaría la existencia de cuatro columnas en la fachada del edificio sacro, pues esta sería la cantidad de soportes que se hallarían en el perímetro del altar $^{33}$. A favor de este planteamiento aboga la tipología de la basa de piedra de mina, un modelo precedente estilísticamente a las basas con plinto de la fachada del templo. Sin embargo, este hecho supondría la erección de una primera construcción religiosa de tipo tetrástilo, transformada en un edificio dístilo e in antis en un periodo ulterior ya que, como se ha venido señalando anteriormente, solo fue hallada la huella de un plinto en la mitad oriental de la fachada del edificio, conllevando por tanto, que las antas del edificio se adelantasen hasta la

30. Tales como los templa forenses de Augusta Emerita («templo de Diana»), Barcino, Carteia, el tetrástilo de Augustobriga, o el Arco de Bará.

31. A esta segunda fase de monumentalización podrían también corresponder una serie de placas marmóreas, de distintos tamaños y grosores halladas en el entorno del templo, que pudieran haber servido como placas de revestimiento de la construcción sacra (Molina, 2003: 61).

32. Recordemos que las basas de tipo ático sin plinto con imoscapo tallado en un mismo bloque son un modelo precedente a las basas áticas definidas como «canónicas» en cuya configuración se ha eliminado el imoscapo y se ha añadido el plinto.

33. A pesar de que solo se ha conservado una de estas piezas (U.E. 13), debemos suponer la existencia de otras tres, que sustentarían la estructura ornamental. 
línea de fachada para cubrir la función tectónica. Este proceso resulta un tanto incongruente en la evolución tipológica habitual de la edilicia sacra romana, pues los edificios in antis se consideran el tipo de edificación religiosa más rudimentario, del que derivan construcciones más complejas (Santos, 1998: 91). Por ello, no consideramos factible la posibilidad de construir un primer edificio de tipo tetrástilo para en una fase más avanzada, modificarlo a una tipología más primitiva como la dístila e in antis.

En relación con la función del complejo y la dedicación del templo, no contamos con testimonios epigráficos ni escultóricos que puedan servirnos como instrumentos para valorar estas cuestiones. Sin embargo, apelaremos a los datos disponibles tales como las dimensiones o la propia situación del recinto dentro del parcelario urbano, para plantear nuestras hipótesis sobre este particular. En efecto, resulta un hecho evidente que sus modestas dimensiones, su situación aislada, limitado en el extremo Oeste por el trazado de la muralla, su adecuación a un solar preexistente y su lejanía de los centros de poder de la ciudad, nos indican su carácter secundario. Se trata pues de un pequeño recinto que daría cobertura a un barrio o a un colectivo no muy numeroso. En este sentido tendríamos que pensar en la titularidad del terreno donde se edifica el complejo, pues se encuentra en una zona de la ciudad de reciente ampliación, muy próximo al intervallum y con la orientación propia de la nova urbs. De haber sido una iniciativa trazada en el marco del ensanche hacia el río, deberíamos suponer la reserva de los terrenos necesarios que hicieran posible una articulación cómoda y organizada del recinto. Sin embargo, nuestro caso plantea otros interrogantes, pues las estructuras parecen adaptarse o ajustarse a un solar precedente, aprovechando el espacio disponible, casi «encajándose» entre la muralla por el extremo Oeste y las hipotéticas vías que lo circundarían por el Este, Norte y Sur. Tampoco se han hallado niveles de arrasamiento o destrucción previos que pudieran haber supuesto un cambio de propiedad y condiciones de los terrenos tras haber sufrido un proceso traumático, por lo que deberíamos pensar en otras opciones como la compra, expropiación o donación del solar.

En principio, y con los testimonios que contamos, resulta harto complicado dilucidar sobre la naturaleza del terreno donde se construye este recinto. Tanto los espacios públicos, semipúblicos o privados podían albergar este tipo de construcciones de uso religioso, pues bien pudiera responder a un pequeño complejo que rindiese culto a alguna divinidad tutelar de la ciu$\operatorname{dad}^{34} \mathrm{o}$ relacionada con las actividades desarrolladas en el sector urbano donde se ubica.

34. Este es el caso del ya mencionado santuario urbano de Tutela en Tarragona, erigido en los primeros decenios del siglo I d.C., y delimitado por el extremo sur del recinto por la muralla republicana.
De otro lado, conviene destacar que este tipo recintos solían ser empleados por los collegia o corporaciones profesionales para el desarrollo de sus reuniones periódicas y actividades relacionadas con sus funciones. Es importante recordar aquí, que independientemente de la tipología de asociación que fuese (colegios religiosos, asociaciones políticas, círculos de diversión, corporaciones profesionales, funerarios etc), todos los colegios romanos tienen siempre un carácter religioso que aglutina a sus miembros bajo la advocación y protección de una divinidad concreta (Waltzing, 1895-1900: 195-196; Santero, 1978: 48; Díaz, 2004: 449; Rodríguez et al., 2016). Será precisamente el culto colegial, el principal elemento definidor de la arquitectura de las sedes (Subías, 1994: 91), aunque no será el único, pues este tipo de agrupaciones requerían de espacios acondicionados con determinados elementos que les permitieran el desarrollo favorable de sus ceremonias.

Ciertamente no existe una tipología arquitectónica definida y concreta que relacionar con estos colectivos, pues la variedad de los restos arquitectónicos identificados, con mayor o menor acierto, como sedes de collegia en el mundo romano, es muy amplia y compleja. Así encontramos edificios semejantes a casas que comparten características comunes como atrios porticados o espacios de recepción como la sede del collegium del foro de Valentia (Escrivá et al., 2013: 64), el conocido «Edifice des Saisons» en Sufetula, Sbeitla (Tunez), o la Sede de los Augustales en Ostia (Italia), sin olvidar tampoco estructuras más complejas como el campamento legionario de Lambaesis o la «Maison de Bacchus» en Djémila (Argelia) (Carrillo, 1995). Otros en cambio, ofrecen una morfología determinada por la presencia de un templo o aedes, que suele presidir un entorno porticado o temenos, en el que se inserta en muchas ocasiones, un altar, como sucede en algunos ejemplos de sedes colegiales conservados en Ostia, tales como el «Aula dei Mensores» (Fig. 10), o ya en Hispania, el edificio interpretado como sede de los augustales de Carthago Nova (Noguera, 2002; Noguera et al., 2013: 140).

En todos los tipos conocidos podemos observar la existencia de unas características mínimas comunes que los hacen aptos para el desarrollo de las actividades propias de las corporaciones. Es fundamental que contengan un espacio abierto y porticado para las reuniones, un lugar de culto, especialmente templos y estancias que permitan la preparación y celebración de los epula o banquetes organizados en dichos encuentros. Así podemos corroborar que el recinto hallado en la calle Tejón y Marín (Córdoba) reúne todas estas condiciones, aunque no por ello podamos afirmar de forma contundente, que se trata de la sede de un collegium, puesto que en este caso y debido a la escasez de los restos arqueológicos conservados, solo podemos aferrarnos al análisis arquitectónico para su 


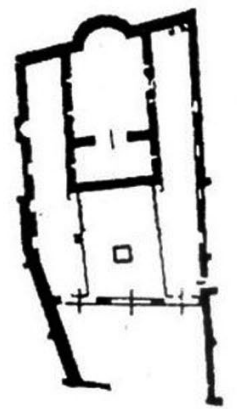

1

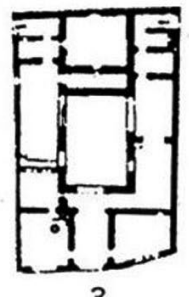

3
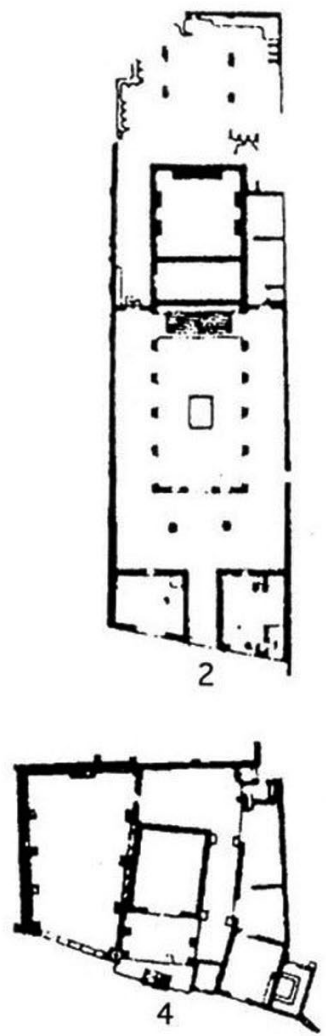

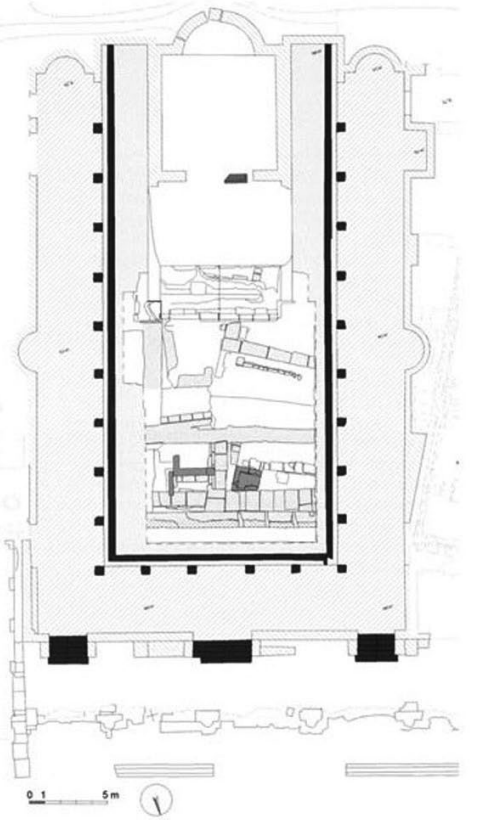

Figura 10: A la izquierda, templos colegiales en Ostia. 1. V, XII - 2. III,II,2 - 3. I, X,4 - 4. Aula dei Mensores (Subías, 1995: 110, fig. 3); a la derecha, planta del templo con pórtico del foro de Cumas. Modificado a partir de Papa, 2009: 299, fig. 4.

reconocimiento ${ }^{35}$. En cualquier caso, pensamos que se trata de una de las posibilidades a tener en cuenta para su correcta interpretación.

Pero de ser válida esta hipótesis, ¿qué sabemos sobre los collegia de Colonia Patricia? El fenómeno asociativo surge en la etapa tardorrepublicana, encauzándose legalmente durante el principado de Augusto (Subías, 1994: 85). Sin duda, la profesión se convirtió en el nexo principal de unión de estas asociaciones y su creación estaba basada en la protección de un oficio, el perfeccionamiento de las técnicas de trabajo y la evolución profesional. En muchos casos estos grupos estaban potenciados por las administraciones del Estado, quienes se beneficiaban en gran medida de la existencia de estos colectivos por su ineludible

35. Hasta la fecha, el único edificio cordobés interpretado hipotéticamente como un collegium es un inmueble situado inmediatamente al Norte del foro colonial, y del que conocemos un patio al que se abrían varias estancias y ambientes; el estanque de un pseudoperistilo, y una sala rectangular rematada por un ábside. Se trata de un edificio existente desde, al menos, inicios del siglo I y cuyo aparato decorativo pudo haber sido remodelado hacia la primera mitadmediados del siglo II (Ruiz Bueno, 2016: 89 y 156). Aun cuando su funcionalidad exacta no ha podido ser determinada, para A. Ventura (2009: 393) «tal vez podría tratarse de la sede de un collegium, pero debe investigarse con mayor detenimiento». utilidad pública (Santero, 1978: 113-114). Por ello, las ciudades provinciales del Imperio impulsarán la creación de estas agrupaciones y en especial, de aquellas que repercutían de forma positiva en el desarrollo de la vida municipal, estos son los denominados tria collegia principalia integrados por los fabri (relacionados con la construcción), centonarii (fabricantes de centones o tela de múltiples aplicaciones) y dendrophori (trabajadores de la industria de la madera).

En Córdoba contamos con algunos testimonios epigráficos relacionados con distintos tipos de agrupaciones, mayoritariamente de carácter funerario (MMAP, XV (1954), 155-56; CIL II, 2.229; CIL II, 2.238; CIL II, 2.248; CIL II, 2.285, etc.). Además, también se conservan dos documentos que nos informan de la existencia de un colectivo profesional asociado, en este caso, a $\operatorname{los} f a b r i^{36}$. Uno de ellos fue recuperado en la localidad cordobesa de Cañete de las Torres hacia 1980 y se presenta en una lámina de bronce escrita por ambas caras, como una tabula de hospitium en la que encontramos una cooptatio patroni efectuada por un collegium de Córdoba en el año 247 d.C. En el documento, los fabri

36. El término fabri es de carácter genérico y engloba a cualquier tipo de obrero, razón por la que habitualmente suele acompañarse de algún término complementario que especifique la actividad desempeñada por este colectivo. 
subediani $^{37}$ de Colonia Patricia eligen como patrono a Bellus Licinianius, seguramente un magistrado local (Rodríguez Neila y Santero, 1982: 163).

El segundo epígrafe consiste una tessera patro$n^{n} a t u s^{38}$, dedicada por la misma corporación, los fabri subidiani de la ciudad, a su patrono Iulius Caninius, en el año 349 d.C. (CIL II ${ }^{2 / 7}$, 332; CIL II, 2211, p. 1049; ILS 7222). En ambos documentos advertimos la presencia del colectivo de los fabri, definidos como subediani en la inscripción de Cañete de las Torres o subidiani en el caso de la capital cordobesa ${ }^{39}$. Sin embargo esta circunstancia responde a una evolución fonética del término sub aediani, constatado epigráficamente en una inscripción del año 149 d.C. procedente de Narbona, que en nuestra opinión y siguiendo la línea interpretativa encabezada por L. Sigal (1924), haría referencia al lugar de reunión de dicho colectivo (aedes). En relación a la primera inscripción, si tenemos en consideración que este tipo de documentos se elaboraban por duplicado, permaneciendo una de las copias en la residencia del patronus y siendo la restante situada en la sede del collegium, debemos pensar que dicha construcción, aedes o schola ${ }^{40}$, se ubicaría en Colonia Patricia y por tanto, el testimonio procedente de Cañete correspondería, probablemente, a la

37. Waltzing aboga por la interpretación de estos fabri subediani o subidiani como carpinteros y ebanistas, mientras que Thouvenot la amplía a estucadores, mosaístas y pintores que decoraban el interior de las casas. No obstante, Hübner y Sigal opinan que los fabri subidiani o subaediani recibirían este nombre en relación con el lugar donde se reunían (aedes) y no por la profesión que ejercían (Waltzing, 18951900: tomo I, 285, II, 122 y 151 y IV, 89; Thouvenot, 1973: 276; Hübner, CIL II, 2.21; Sigal, 1924: 141-156).

38. Las Tábulas de Patronato son documentos elaborados en láminas de bronce que conmemoran acuerdos de hospitium o patronatus, que comprometen a una ciudad y a un individuo o bien, a imagen y semejanza de estas, a un collegium y un individuo. Uno de los rasgos característicos de esta tipología epigráfica es su elaboración por duplicado, de forma que uno de los ejemplares fuese conservado por el hospes-patronus, quien la colocaba habitualmente en un lugar destacado de su morada, mientras que el restante se ubicaba en un espacio público por parte de la entidad emisora (Díaz, 2014: 227).

39. En el caso del documento de Córdoba capital, es importante señalar el total desconocimiento en cuanto a la zona de la ciudad donde fue hallada, ya que aparece reflejado como un hallazgo fortuito sin especificar la ubicación del descubrimiento en el entramado urbano.

40. El término aedes hace referencia a un edificio destinado al culto de una divinidad, si bien su significado original lo vincula a casa o habitación elevada destinada a la estancia de una deidad. Por otro lado, el término schola designa una estructura con forma de exedra o semicircular, habitualmente acompañada de un banco corrido, empleada en distintos ámbitos (funerario, religioso, corporativo, etc) para diferentes usos. Sin embargo, según algunos especialistas como Waltzing (1895-1900: 227), el término schola era un sinónimo de templo (Subías, 1994: 100). reproducción que conservaría el patrono en su casa (Rodríguez y Santero, 1982: 160).

En síntesis, estos testimonios epigráficos dan prueba de la existencia de este colectivo en la ciudad con su correspondiente sede, presumiblemente una aedes. Aun cuando la similitud arquitectónica observada entre el recinto cordobés y algunas sedes de collegia, especialmente de determinados ejemplares hallados en Ostia (Fig. 10), nos impulsa a valorarlo como uno de estos centros, estas semejanzas arquitectónicas no son suficientes argumentos para refrendar esta interpretación, dejando abierta otras posibilidades. Tampoco tenemos garantía de que, de tratarse de una sede colegial, correspondiese al caso concreto de los fabri subaediani, con los que lo hemos relacionado por el supuesto uso de un recinto religioso similar al que analizamos y por la constancia epigráfica de los mismos en la ciudad.

En cualquier caso, independientemente de que se tratase de un recinto público o semipúblico dedicado a alguna divinidad tutelar de la ciudad, a cualquier deidad relacionada con las actividades desarrolladas en este sector de la urbe, o bien de la sede de un collegium, creemos que la importancia y singularidad del complejo cordobés de la calle Tejón y Marín reside en tratarse de uno de los escasos ejemplares de recintos religiosos urbanos localizados en Hispania y, por consiguiente, es fundamental ser conscientes de su existencia ya que además, nos encontraríamos ante el recinto religioso más antiguo documentado arqueológicamente, hasta el momento, en la ciudad de Córdoba $^{41}$. Únicamente contamos con dos casos hispanos más documentados: los santuarios urbanos de Tutela Tarraconensis en Tarraco ${ }^{42}$, datado en los primeros decenios del siglo I d.C. (Mar et al., 2015: 328-335) y el lusitano dedicado a Fontano y Fontilis en Contributa Iulia, perteneciente a finales del siglo I d.C. (Mateos y Pizzo, 2015). Estos ejemplos se convierten en la evidencia de un tipo de recintos cerrados e independientes, con usos y funciones propias, que conviven en el interior de las ciudades con los principales espacios de representación donde se insertan, habitualmente, los

41. Los primeros edificios religiosos erigidos en la Córdoba romana debieron ubicarse, muy probablemente, en el entorno del foro colonial, al ser este el primitivo espacio público de la ciudad republicana. Sin embargo, estas construcciones no han sido documentadas arqueológicamente hasta el momento, motivo por el cual el recinto de la calle Tejón y Marín se convertiría en el ejemplar más remoto de los templa cordobeses.

42. Como hemos venido señalando, el recinto cordobés guarda ciertas similitudes con el tarraconense, perceptibles tanto en el tipo de planta del edificio principal, como en la inserción urbanística del recinto, ya que en ambos casos estos complejos se encuentran limitados en uno de sus extremos por la muralla de la ciudad (por el Sur en el caso del santuario de Tutela Tarraconensis y por el Oeste en el ejemplar cordobés). 

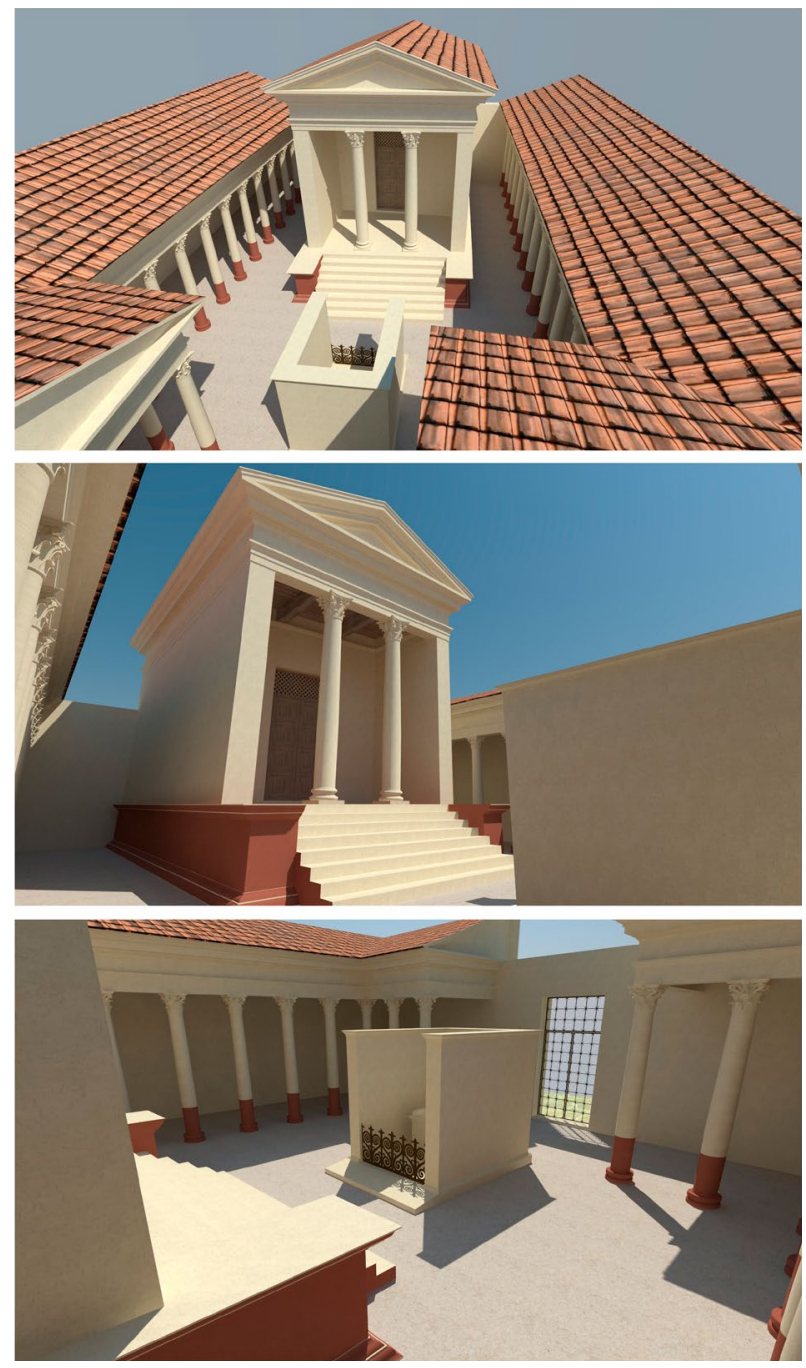

Figura 11: Reconstrucción ideal del recinto sacro cordobés de la calle Tejón y Marín a finales del siglo I a.C. (Autoría: J. Ma . Tamajón. Asesoramiento científico: A. Portillo y M. D. Ruiz)

edificios religiosos principales de cada enclave. Fuera del ámbito hispano existen numerosos ejemplos de santuarios o recintos religiosos urbanos de esta tipología, muchos de ellos ubicados en las inmediaciones de los foros de las ciudades, tales como el templo de Apolo o el edificio de Eumachia en el foro de Pompeya o el templo con pórtico del foro de Cumas (Fig. 10), éste último interpretado como una posible sede de un collegium (Gasparri, 2009; Papa, 2009).

Al margen de su exacta funcionalidad, el recinto sacro de calle Tejón y Marín estuvo en uso durante varios siglos, hasta que en un momento indeterminado del siglo IV d.C. debió de quedar inutilizado. Su abandono y saqueo en dicha centuria no resulta extraño si tenemos en cuenta la evolución de la arquitectura cultual pagana y el impacto del Cristianismo en ella. Ahora bien, en el estado actual de la investigación no contamos con evidencias que reflejen una destrucción violenta y súbita del complejo cordobés por parte de la comunidad cristiana. En el caso
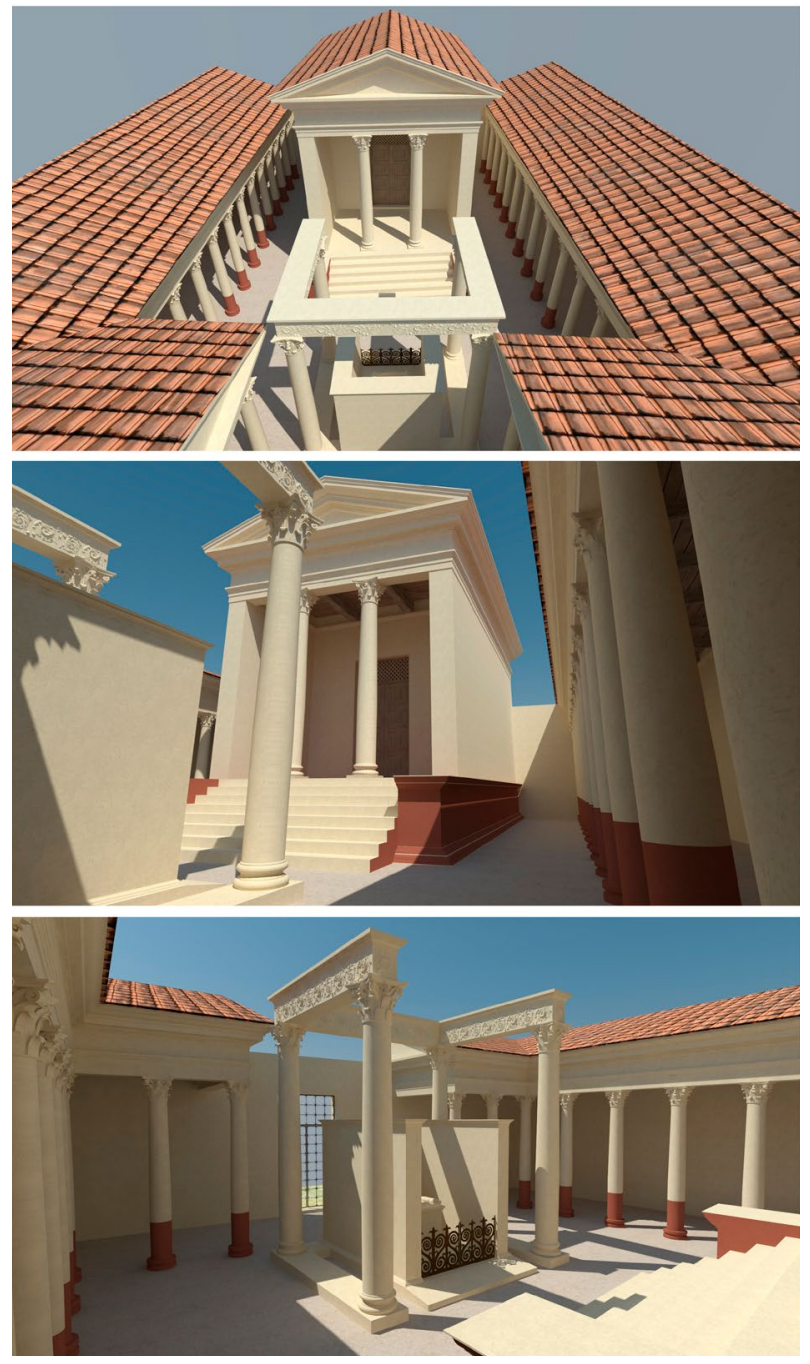

Figura 12: Reconstrucción ideal del recinto sacro cordobés de la calle Tejón y Marín hacia la segunda mitad del siglo I d.C. (Autoría: J. Ma ${ }^{a}$ Tamajón. Asesoramiento científico: A. Portillo y M. D. Ruiz)

de la península ibérica (al igual que en buena parte del Imperio), tales episodios de intolerancia religiosa debieron de ser minoritarios, afectando puntualmente a algunos grupos escultóricos (Correia, 2010: 102; Bernal et al., 2013: 137-141; Garriguet, 2014: 97) y a determinados mosaicos (López Monteagudo y Blázquez, 1990), mientras que los templos parecen haber salido más indemnes. Por si fuera poco, las últimas investigaciones arqueológicas llevadas a cabo reflejan un panorama más complejo del que tradicionalmente se ha venido defendiendo. Así, en Augusta Emerita ha sido descubierto un santuario suburbano (consagrado posiblemente a Cibeles y Atis) cuya destrucción deliberada y apresurada a finales del siglo IV o inicios del V d.C. «fue provocada por los propios seguidores de esta religión, cuyo deseo desesperado era clausurar o sellar ritualmente el santuario de sus dioses» (Heras, 2011: 127).

Tras el expolio parcial del recinto sacro, dicho espacio albergó varias estructuras de funcionalidad 
desconocida y, al menos, una tumba (aunque el número debió de ser mayor). Aun cuando se ha sugerido la influencia de la religio christiana en dicha reocupación funeraria, nuevamente no podemos achacar al Cristianismo la aparición de tales enterramientos ya que, como hemos puesto de relieve, pueden responder a otras causas. A la espera de futuras intervenciones arqueológicas en los solares aledaños, nos parece más factible que nos encontremos ante varias construcciones de carácter residencial y/o productivo cuyos moradores pudieron ser inhumados en el entorno inmediato. Se trata de una modalidad de enterramiento característica de un período como la Antigüedad Tardía, en el que vivos y muertos convivieron sin problemas tanto en el espacio intramuros, como en el suburbio.

Damos por concluido aquí un trabajo cuya intención última es sumar el recinto sacro de la calle Tejón y Marín (Fig. 11 y 12) al elenco de complejos religiosos urbanos de la primera etapa imperial en el contexto hispano.

\section{REFERENCIAS}

Alapont, Ll. y Ribera, A.V. (2009). Topografía y jerarquía funeraria en la Valencia tardoantigua. En J. López y A.M. Martínez (Coords.). Morir en el mediterráneo medieval (pp. 59-88). Oxford: Archaeopress.

Alba, M. (2001). Características del viario urbano de Emerita Augusta entre los siglos I y VIII. Memoria 5: Excavaciones arqueológicas en Mérida, 397-423.

Alba, M. y Mateos, P. (2006). Epílogo: Transformación y ocupación tardoantigua y altomedieval del llamado «foro provincial». En P. Mateos (Ed.). El «foro provincial» de Augusta Emerita: un conjunto monumental de culto imperial (pp. 355-380). Madrid: Consejo Superior de Investigaciones Científicas.

Almeida, D.F. (1964). Ruínas de Miróbriga dos Célticos (Santiago do Cacém). Setúbal: Junta Distrital de Setúbal.

Almoguera, J.M. (2011). El foro colonial. En M $M^{\mathrm{a}}$.D. Baena, C. Márquez y D. Vaquerizo (Eds.). Córdoba, reflejo de Roma. Catálogo de la exposición (pp. 43-50). Córdoba: Ayuntamiento de Córdoba.

Arce, J. (2006). Fana, templa, delubra destrui praecipimus: el final de los templos de la Hispania romana. Archivo Español de Arqueología, 79, 115-124. DOI: http://dx.doi. org/10.3989/aespa.2006.v79.6

Arnau, B., García, Mª.I., Ruiz, E., y Serrano, L. (2005). Nuevos datos sobre la necrópolis occidental de la Antigüedad Tardía (Valencia). En J.Mª . Gurt y A.V. Ribera (Coords.). VI Reunió d'Arqueologia Cristiana Hispànica (pp. 261-266). Barcelona: Institut d’Estudis Catalan.

Azkarate, A. (2002). De la tardoantigüedad al medievo cristiano. Una mirada a los estudios arqueológicos sobre el mundo funerario. En D. Vaquerizo (Ed.). Espacios y usos funerarios en el Occidente romano: Actas del Congreso Internacional (pp. 115-140). Córdoba: Universidad de Córdoba.
Barata, M. F. (2010). Caracterizaçao Geral de Miróbriga. En T. Nogales (Ed.). Ciudad y foro en Lusitania Romana. (pp. 201-230). Mérida: Museo Nacional de Arte Romano.

Barroso, R.A. (2015). La religión provincial romana en el conventus Cordubensis: un análisis a través de la epigrafia votiva. (Trabajo Fin de Grado inédito). Universidad de Córdoba. Córdoba.

Bayliss, R. (2001). Provincial Cilicia and the Archeology of Temple Conversion (Tesis Doctoral Inédita). Universidad de Newcastle. Newcastle. Recuperado de: https://theses.ncl. ac.uk/dspace/handle/10443/575

Beltrán. J. (2013). Barcino, de colònia romana a sede regia visigoda, medina islàmica i ciutat comtal: una urbs en transformació. Quarhis, 9, 16-118.

Beltrán. J. (2015). Novetats sobre el fórum de Barcino: la cúria i altres edificis públics. Quarhis, 11, 126-146.

Bernal, D. (2006). Carteia en la Antigüedad Tardía. En L. Roldán, M. Bendala, J. Blánquez y S. Martínez (Dirs.). Estudio histórico-arqueológico de la ciudad de Carteia (San Roque, Cádiz), 1994-1999, vol. I (pp. 417-464). Sevilla y Madrid: Junta de Andalucía y Universidad Complutense de Madrid.

Bernal, D., Arévalo, A., Díaz, J.J., Lagóstena, J., Vargas, J.M., Lara, M.,... y Muñoz, A. (2013). Las termas y el $s u$ burbium marítimo de Baelo Claudia. Avance de un reciente descubrimiento. Onoba, 1, 115-152.

Borrego, J. y Felipe, A. (2014). La decoración arquitectónica. En C. Márquez, J.A. Morena, A. Ventura y R. Córdoba (Eds.). Torreparedones: investigaciones arqueológicas (2006-2012) (pp. 99-109). Córdoba y Baena: Universidad de Córdoba y Ayuntamiento de Baena.

Burgholzer, G. (1994). Templos in antis de la Península Ibérica. En X. Dupré (Coord.). Actas del XIV Congreso Internacional de Arqueología Clásica, II (pp. 78-79). Tarragona: Consejo Superior de Investigaciones Científicas.

Carrillo, J.R. (1995). Las sedes de corporaciones en el mundo romano: un problema de identificación arqueológica. Anales de Arqueología Cordobesa, 6, 29-77.

Carrillo, J.R., Hidalgo, R., Murillo, J.F. y Ventura, A. (1999). Córdoba de los orígenes a la Antigüedad Tardía. En F.R. García, y F. Acosta (Coords.). Córdoba en la historia: la construcción de la urbe (pp. 37-74). Córdoba: Ayuntamiento de Córdoba.

Caseau, B. (2001). La désacralisation des espaces et des objects religieux païens durante l'antiquité tardive. En M. Kaplan (Ed.). Le sacré et son inscription dans l'espace à Byzance et en Occident. Études comparées (pp. 61-123). Paris: Publications de la Sorbonne.

Correia, V.H. (2010). O forum de Conimbriga e a evolução do centro urbano. En T. Nogales (Ed.). Ciudad y foro en Lusitania Romana (pp. 89-105). Mérida: Museo Nacional de Arte Romano.

Crozzoli, L. (1981). I tre templi del Foro Olitorio. Roma: L'Erma di Bretschneider. 
De la Barrera, J.L. (2000). La decoración arquitectónica de los foros de Augusta Emerita. Roma: L'Erma di Bretschneider.

De Man, A. (2005). Sobre a Cristianização de um Forum. Al-Madan, 13, 43-46. Recuperado de: https://issuu.com/ almadan/docs/almadan online 13

De Robertis, F. M. (1934). Storia delle corporazioni e del regime associativo nel mondo romano. Bari: Adriatica.

Díaz, B. (2004). Heisce Magistreis. Aproximación a los collegia de la Hispania republicana a través de sus paralelos italianos y delios. Gerion, 22. 2, 447-478.

Díaz, B. (2014). Patrono suo dedicavit. La evolución de las tábulas de patronato en época tardía. En A. Duplá, $M^{a}$ V. Escribano, L. Sancho y $\mathrm{M}^{\mathrm{a}}$ A. Villacampa (Eds.). Miscelánea de estudios en homenaje a G. Fatás Cabeza (pp. 227-234). Zaragoza: Institución Fernando el Católico.

Escrivá, M. I. (2005). Basas romanas de la «Provincia Tarraconensis». Valencia: Institució Alfons El Magnànim.

Escrivá, M.I., Jiménez, J.L. y Ribera, A. (2013). La curia y la basílica de Valentia. En B. Soler, P. Mateos, J.M. Noguera y J. Ruiz de Arbulo (Coords.). Las sedes de los ordines decurionum en Hispania: análisis arquitectónico y modelo tipológico (pp. 53-67). Mérida: Consejo Superior de Investigaciones Científicas e Instituto de Arqueología de Mérida.

Fernández, J. (2009). Privilegios episcopales y genealogía de la intolerancia cristiana en época de Constantino. Pyrenae, 40(1), 81-119.

Foschia, L. (2009). The preservation, restoration and (re) construction of pagan cult places in Late Antiquity, with particular attention to mainland Greece (Fourth-Fifth Centuries). Journal of Late Antiquity, 2(2), 209-223. DOI: https:// doi.org/10.1353/jla.0.0052

Frade, H. (1990). Novos elementos sobre o templo romano de Almofala. Conimbriga, 29, 91-101.

Frade, H. (2010). Os fora de Bobadela (Oliveira do Hospital) e da Civitas Colbecorum (Figeira de Castelo Rodrigo). En T. Nogales (Ed.). Ciudad y foro en Lusitania Romana (pp. 47-68). Mérida: Museo Nacional de Arte Romano.

García-Dils, S. (2015). Colonia Augusta Firma Astigi. La evolución urbana de Écija desde la Protohistoria hasta la Antigüedad Tardía. Sevilla: Universidad de Sevilla.

García-Dils, S., Ordóñez, S. y Rodríguez, O. (2007). Nuevo templo augusteo en la Colonia Augusta Firma Astigi (Écija - Sevilla). Romula, 6, 75-114.

Garriguet, J.A. (2014). Imágenes sin poder. Destrucción, reutilización y abandono de estatuas romanas en la Corduba tardoantigua. Algunos ejemplos. En D. Vaquerizo, J.A. Garriguet y A. León (Eds.). Ciudad y territorio: transformaciones materiales e ideológicas entre la época clásica y el Altomedievo (pp. 85-104). Córdoba: Universidad de Córdoba.

Garriguet, J.A. (2015). Sobre el modelo, cronología y posible dedicación del templo romano de c/ Claudio Marcelo, Córdoba. Apuntes arqueológicos e históricos. Antigüedad: religiones y sociedades, 12, 238-267.
Gasparri, C. (2009). Il foro di Cumae: un bilancio preliminare. En G. Gasparri y G. Greco (A cura di). Cuma. Indagini archeologiche e nuove scoperte (pp. 131-147). Pozzuoli: Naus Editora.

Godoy, F. (1996). El conocimiento de Colonia Patricia a través de los fondos del Museo Arqueológico de Córdoba. En P. León (Ed.). Colonia Patricia Corduba: una reflexión arqueológica (pp. 249-258), Sevilla: Junta de Andalucía.

Goodman, P.J. (2011). Temples in Late Antique Gaul. En L. Lavan y M. Mulryan (Eds.). The Archeology of Late Antique «Paganism» (pp. 165-193). Leiden-Boston: Brill.

Gros, P. (2001). L'Architecture romaine: du debut du IIIe siècle a v. J-C à la fin du haut empire, vol. 1, Les monuments publics. París: Picard.

Gutiérrez, Mª I. (2012). Aproximación a los materiales pétreos de la gran arquitectura de Colonia Patricia Corduba. En V. García-Entero (Ed.). El marmor en Hispania: explotación, uso y difusión en época romana (pp. 299-314). Madrid: Universidad Nacional de Educación a distancia.

Gutiérrez, Ma . I. (2016). Análisis de un centro de culto imperial de la Córdoba romana: el conjunto arquitectónico de la c/ Claudio Marcelo. (Tesis Doctoral Inédita). Universidad de Córdoba. Córdoba. Recuperado de: http://helvia.uco.es/ xmlui/handle/10396/13241

Heras, F.J. (2011). Un edificio singular de la Mérida tardorromana: un posible centro de culto metróaco y rituales taurobólicos. Mérida: Asamblea de Extremadura.

Lavan, L. (2011). The end of the temples: towards a new narrative? En L. Lavan y M. Mulryan (Eds.). The Archeology of Late Antique «Paganism» (pp. 15-65). Leiden-Boston: Brill.

López Monteagudo, G. y Blázquez, J.Mª (1990). Destrucción de mosaicos mitológicos por los cristianos. Antigüedad y Cristianismo, 7, 353-365.

López Quiroga, J. (2013). De Conimbriga a Condeixa. Evolución y transformación de una civitas romana en una «aldea» medieval. En J. López (Ed.). Conimbriga tardo-antigua y medieval. Excavaciones arqueológicas en la domus tancinus (2004-2008) (Condeixa-a-Velha, Portugal (pp. 319-341). Oxford. Archaeopress.

López Quiroga, J., y Martínez, A.M. (2006): El destino de los templos paganos en Hispania durante la Antigüedad Tardía. Archivo Español de Arqueología, 79, 125-153. DOI: http://dx.doi.org/10.3989/aespa.2006.v79.7

Macias, J.M. (2014). El territorio y la ciudad de Tarraco. En P. Pensabene y C. Sfameni (Coords.). La villa restaurata e i nuovi studi sull'edilizia residenziale tardoantica (pp. 453465). Bari: Edipuglia.

Mar, R., Ruiz, J., Vivó, D., y Beltrán, J. (2015). Tarraco. Arquitectura y urbanismo de una capital provincial romana, vol. I. De la Tarragona ibérica a la construcción del templo de Augusto. Tarragona: Publicacions de la Universitat Rovira i Virgili.

Márquez, C. (1998). La decoración arquitectónica de Colonia Patricia. Una aproximación a la arquitectura y 
urbanismo de la Córdoba romana, Córdoba: Universidad de Córdoba y Caja de Ahorros y monte de Piedad de Córdoba.

Mateos, P. y Pizzo, A. (2015). Un santuario urbano hallado en Contributa Iulia (Medina de las Torres, Badajoz). Lucentum, 34, 231-246. DOI: http://dx.doi.org/10.14198/ LVCENTVM2015.34.09

Molina, A. (2003). Informe-Memoria de la Intervención Arqueológica de Urgencia en calle Tejón y Marín $n^{\circ}$ 14, Córdoba. Informe administrativo (inédito) depositado en la Gerencia Municipal de Urbanismo del Ayuntamiento de Córdoba. Córdoba.

Monterroso, A.J. y Cepillo, J.J. (2002). La ocupación medieval. En A. Ventura, C. Márquez, A. Monterroso y M.A. Carmona (Eds.). El teatro romano de Córdoba. Catálogo de la exposición (pp. 161-172). Córdoba: Universidad de Córdoba.

Murillo, J.F. (2010). Colonia Patricia Corduba hasta la dinastía flavia. Imagen urbana de una capital provincial. En R. González y J. Ruiz (Eds.) Simulacra Romae II. Rome, les capitales de province (capita prouinciarum) et la création d'un espace commun européen. Une approche archéologique (pp. 71-93). Reims: Société archéologique champenoise.

Murillo, J.F., Ruiz, Mª.D., Carmona, S. y Moreno, M. (2009). La manzana de San Pablo-Orive en el contexto de la evolución histórico-urbanística de la ciudad de Córdoba. En Orive. La clave del espacio público en el Centro Histórico de Córdoba (pp. 43-136). Córdoba: Ediciones de la Posada.

Noguera, J.M. (2002). Un edificio del centro monumental de Carthago Nova: Análisis arquitectónico-decorativo e hipótesis interpretativas. Journal of Roman Archaeology, 15, 63-96. DOI: https://doi.org/10.1017/S1047759400013842

Noguera, J.M., Martín, M. y Soler, B. (2013). De nuevo sobre el foro de Carthago Nova: la curia de la colonia. En B. Soler, P. Mateos, J.M. Noguera y J. Ruiz de Arbulo (Coords.). Las sedes de los ordines decurionum en Hispania: análisis arquitectónico y modelo tipológico (pp. 135163). Mérida: Consejo Superior de Investigaciones Científicas e Instituto de Arqueología.

Orfila, M., Cau, M.A., y Chávez, E. (2006). La ciudad romana de Pollentia (Alcudia, Mallorca). Resultados de la investigación entre 1996-2004. Tabona, 14, 93-115.

Papa. L. (2009). Metodologia per una campagna di rilievo e rappresentazione del construito archeologico: il caso del Tempio con Portico a Cuma. En G. Gasparri y G. Greco (A cura di), Cuma. Indagini archeologiche e nuove scoperte (pp. 293-299). Pozzuoli: Naus Editora.

Pensabene, P. (2013). I marmi antichi della Roma antica, Roma: Carocci.

Portillo, A. (2016). El templo de la calle Morería en el Forum Novum de Colonia Patricia. Análisis arquitectónico y funcional. (Tesis Doctoral Inédita). Universidad de Córdoba. Córdoba. Recuperado de: http://helvia.uco.es/xmlui/ handle/10396/13226

Rascón, S. y Sánchez, A.L. (2015): Complutum: modelo urbanístico para una ciudad romana privilegiada en los siglos III-V. En L. Brassous y A. Quevedo (Eds.). Urbanisme civique en temps de crise. Les espaces publics d'Hispanie et de l'Occident romain entre les II et IV siècles (pp. 199220). Madrid: Casa de Velázquez.

Rodríguez Neila, J.F. y Santero, J.M. (1982). Hospitum y Patronatus sobre una tabla de bronce de Cañete de las Torres (Córdoba), Habis, 13, 105-164.

Rodríguez Oliva, O., Tran, N. y Soler B. (Eds.). (2016). Los espacios de reunión de las asociaciones romanas. Diálogos desde la arqueología y la historia, en homenaje a Bertrand Goffaux. Sevilla: Universidad de Sevilla.

Ruiz Bueno, M.D. (2016). Topografia, imagen y evolución urbanistica de la Córdoba clásica a la tardoantigua (ss. II-VII d.C.). (Tesis Doctoral Inédita). Universidad de Córdoba. Córdoba. Recuperado de: http://helvia.uco.es/xmlui/ handle/10396/14142

Ruiz Bueno, M.D. (2017). Enterramientos hispanos tardoantiguos in urbe: algunas reflexiones y tendencias. En P. Diarte (Ed.). Cities, Lands and Ports in Late Antiquity and the Early Middle Ages: Archaeologies of Change (pp. 2328). Roma: BraDypUS.

Ruiz Lara, M‥D., Moreno, M., Carmona, S., Vargas, S. y Murillo, J.F. (2004). Informe-memoria de la I.A.U. en apoyo de la restauración y puesta en valor de las murallas de Córdoba en el sector de la Puerta de Almodóvar. Informe administrativo (inédito) depositado en la Gerencia Municipal de Urbanismo del Ayuntamiento de Córdoba. Córdoba.

Sánchez, I. Ma (2006). La cristianización de la topografía funeraria en las provincias occidental del Imperio: exemplum cordubense. (Tesis Doctoral Inédita). Universidad de Córdoba. Córdoba. Recuperado de http://helvia.uco.es/ xmlui/handle/10396/3657

Sánchez, I. Mª (2010). Corduba durante la Antigüedad tardía. Las necrópolis urbanas. Oxford: Archaeopress.

Santero, J.M. (1978). Asociaciones populares en Hispania Romana. Sevilla: Universidad de Sevilla.

Santos, M.F. (1998). Miróbriga: urbanismo e arquitectura. Lisboa: Instituto Português do Património Arquitectónico.

Sears, G. (2011). The fate of the temples in North Africa. En L. Lavan y M. Mulryan (Eds.). The Archeology of Late Antique «Paganism» (pp. 229-259). Leiden-Boston: Brill.

Sigal, L. (1924). Les fabri subaediani, d'après une inscription du musée de Narbonne. Bulletin de la Comission Archéologique de Narbonne, 16, 141-156.

Subías, E. (1994). Las sedes colegiales en época romana. Problemas de tipología arquitectónica. Boletín Arqueológico Reial Societat Arqueológica Tarraconense, 16, 85-110.

Thouvenot, R. (1973). Essai sur le province romaine de Bétique. Paris: De Boccard.

Van Der Meer, L.B. (2009). The temple of the Piazzale delle Corporazioni in Ostia Antica. Babesch, 84, 163-170.

Vaquerizo, D. (2005). Arqueología de la Córdoba Republicana. En E. Melchor, J. Mellado y J.F. Rodríguez (Eds.). Julio César y Corduba: tiempo y espacio en la campaña de 
Munda (49-45 a.C.) (pp. 165-205). Córdoba: Universidad de Córdoba.

Vaquerizo, D. y Ruiz, M.D. (2014). Últimas investigaciones arqueológicas en Corduba, Colonia Patricia: una propuesta de síntesis. En M. Martín-Bueno y J.C. Sáenz (Eds.). Modelos edilicios y prototipos en la monumentalización de las ciudades de Hispania (pp. 15-31). Zaragoza: Universidad de Zaragoza.

Ventura, A. (2000). Informe sucinto de resultados de la Excavación Arqueológica de Urgencia en los solares destinados a la ampliación del MAEPCO. Informe administrativo (inédito) depositado en la Delegación Provincial de Cultura de la Junta de Andalucía. Córdoba.
Ventura, A. (2009). Las élites de Colonia Patricia, año 5 a.C.: un ejemplo de puesta en escena literaria y monumental. En Espacios, usos y formas de la epigrafia hispana en épocas antigua y tardoantigua. Homenaje al doctor Armin U. Stylow (pp. 375-395). Mérida: Consejo Superior de Investigaciones Científicas e Instituto de Arqueología Mérida.

Verdugo, J. (2003). El Cristianismo en Itálica: fuentes, tradiciones y testimonios arqueológicos. En L.A. García et alii (Eds.). Santos, obispos y reliquias. Actas del III Encuentro Internacional Hispania en la Antigüedad Tardia (pp. 353382). Alcalá de Henares: Universidad de Alcalá de Henares.

Waltzing, J.P. (1895-1990). Étude historique sur les corporations professionnelles chez les Romains depuis les origines jusqu'à la chute de l'Empire d'Occident. Bruselas: Nabu Press. 